\title{
METODOLOGIA PARA A CONDUÇÃO DO TESTE DE GERMINAÇÃO E UTILIZAÇÃO DE RAIOS-X PARA A AVALIAÇÃO DA QUALIDADE DE SEMENTES DE AROEIRA- BRANCA (Lithraea molleoides (Vell.) Engl.)
}

\section{CIBELE FERREIRA MACHADO}

Dissertação apresentada à Escola Superior de Agricultura "Luiz de Queiroz", Universidade de São Paulo, para obtenção do título de Mestre em Agronomia, Área de Concentração: Fitotecnia.

PIRACICABA

Estado de São Paulo - Brasil

Abril - 2002 


\section{METODOLOGIA PARA A CONDUÇÃO DO TESTE DE GERMINAÇÃO E UTILIZAÇÃO DE RAIOS-X PARA A AVALIAÇÃO DA QUALIDADE DE SEMENTES DE AROEIRA- BRANCA (Lithraea molleoides (Vell.) Engl.)}

\section{CIBELE FERREIRA MACHADO}

Engenheira Florestal

Orientador: Prof. Dr. SILVIO MOURE CICERO

Dissertação apresentada à Escola Superior de Agricultura "Luiz de Queiroz", Universidade de São Paulo, para obtenção do título de Mestre em Agronomia, Área de Concentração: Fitotecnia.

PIRACICABA

Estado de São Paulo - Brasil

Abril - 2002 
Dados Internacionais de Catalogação na Publicação (CIP)
DIVISÃO DE BIBLIOTECA E DOCUMENTAÇÃO - ESALO/USP

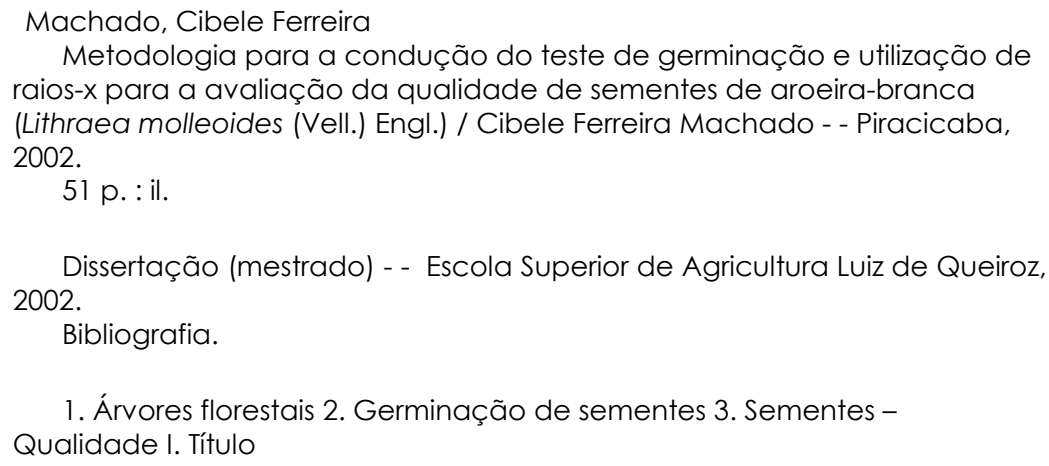

1. Árvores florestais 2. Germinação de sementes 3. Sementes Qualidade I. Título

CDD 634.97328

\section{"Permitida a cópia total ou parcial deste documento, desde que citada a fonte - $O$ autor"}


Aos mentores desta jornada:

meus avós paternos e maternos, in memoriam, meus pais Machado \& Letícia, meu irmão André, e Cláudio, pelo amor e cumplicidade, 


\section{AGRADECIMENTOS}

À Escola Superior de Agricultura "Luiz de Queiroz" (ESALQ), através da Coordenação de Pós-Graduação em Fitotecnia, pela oportunidade de realização do Curso de Mestrado.

Ao Professor Silvio Moure Cicero, pela orientação, incentivo e confiança.

Aos Professores Walter R. da Silva, Ana D.L.C. Novembre e Julio Marcos Filho, pelos ensinamentos e atenção dispensada.

À Engenheira Agrônoma Helena M.C.P. Chamma, pela amizade e contribuições durante a realização deste trabalho.

Ao Conselho Nacional de Desenvolvimento Científico e Tecnológico (CNPq), pela concessão da Bolsa de Mestrado.

Ao Professor Antonio Claudio Davide (UFLA), pela amizade, estímulo e pelo fornecimento das sementes.

Aos Docentes do Setor de Sementes da UFLA, pela disponibilidade e amizade.

Aos funcionários do Departamento de Ciências Florestais/UFLA, José Carlos e Olívia, pela colheita e preparo das sementes.

A Luciana Magda, Viviane, Adriane e Graziela, pelo convívio e amizade.

Aos Funcionários Ilze H.C.G. das Neves, Hodair L. Banzatto Júnior, Luciane A. Lopes Toledo, Roseneide dos Santos, João B. Bigelli, Carlos A. Carlet e João E. Jabur Filho, pelo auxílio durante a realização deste trabalho. 
Aos Funcionários da Biblioteca Central da ESALQ, pelo atendimento e atenção dispensada.

Aos colegas do Curso de Pós-Graduação em Fitotecnia, em especial Maria Cristina, Angélica, Clodoaldo, Daniel, Ebert, José Luís, Magali, Mônica, Nilza Patrícia, Osmar, Roseli, Salvador, Samara, Sílvia e Virgínia, pela amizade e momentos compartilhados. 


\section{SUMÁRIO}

Página

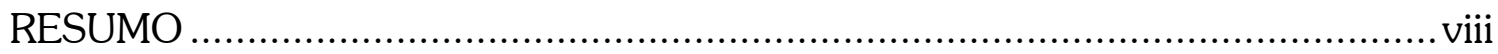

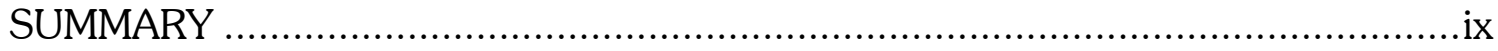

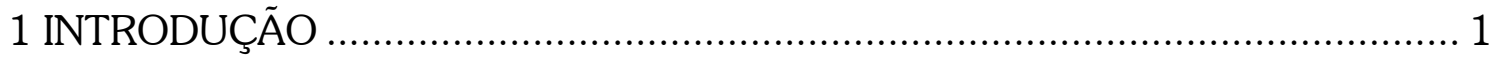

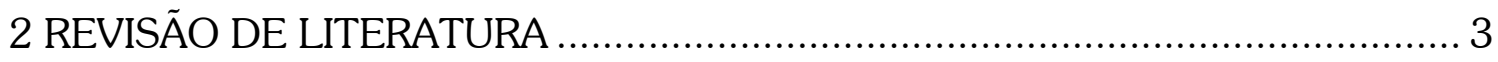

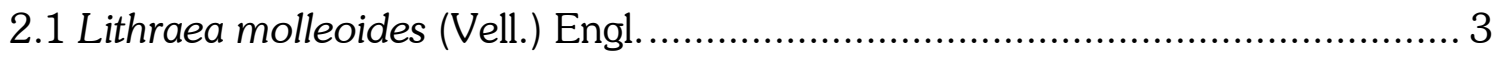

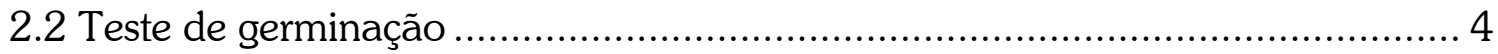

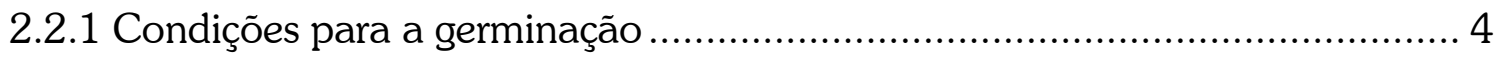

2.2.2 Metodologia para as espécies florestais..................................................... 8

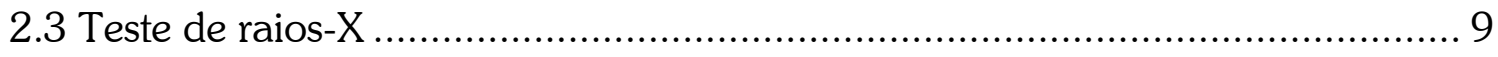

3 METODOLOGIA PARA A CONDUÇÃO DO TESTE DE GERMINAÇÃO EM SEMENTES DE AROEIRA-BRANCA (Lithraea molleoides (Vell.) Engl.) .............. 13

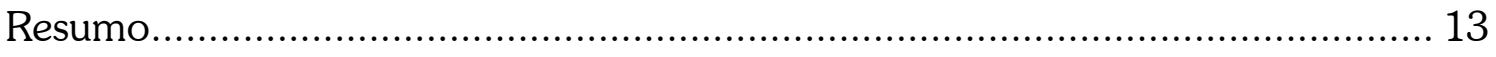

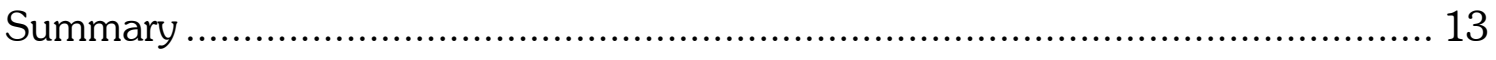

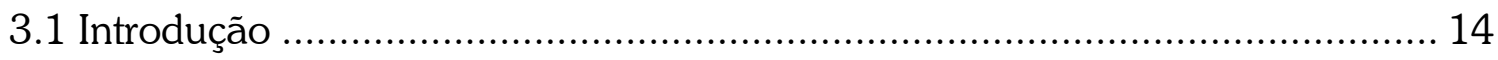

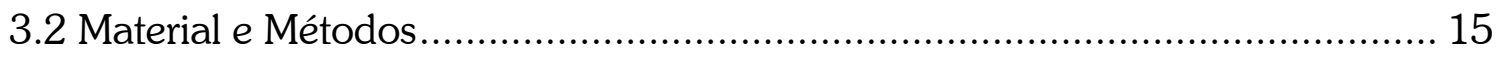

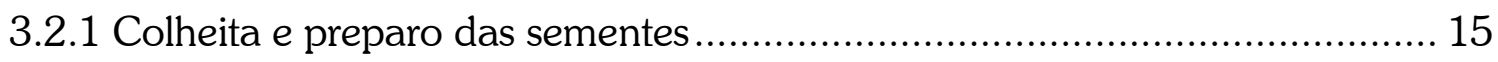

3.2.2 Experimento 1: efeito da temperatura na germinação das sementes............ 16

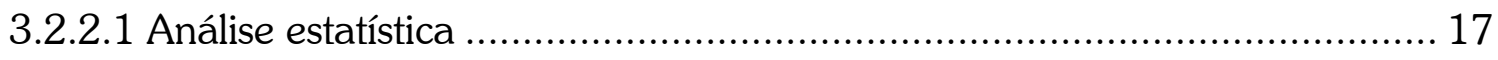

3.2.3 Experimento 2: avaliação de substratos................................................... 17

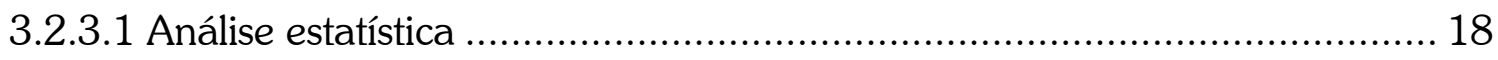

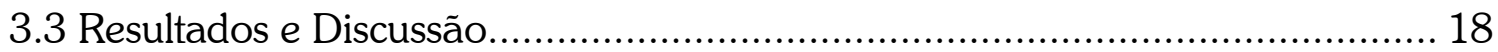


3.3.1 Experimento 1: efeito da temperatura na germinação das sementes 18

3.3.2 Experimento 2: avaliação de substratos................................................... 27

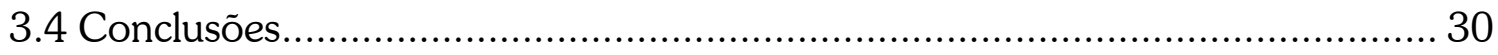

4 UTILIZAÇÃO DO TESTE DE RAIOS-X PARA A AVALIAÇÃO DA QUALIDADE DE SEMENTES DE AROEIRA-BRANCA (Lithraea molleoides (Vell.) Engl.) ........ 31

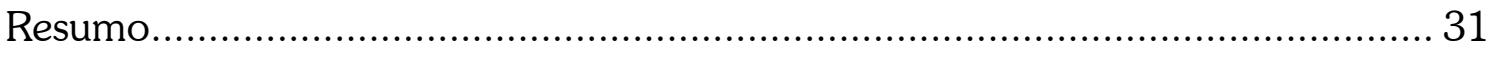

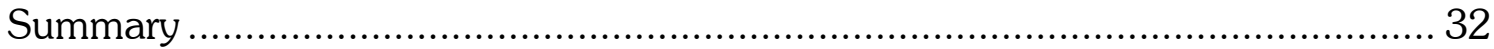

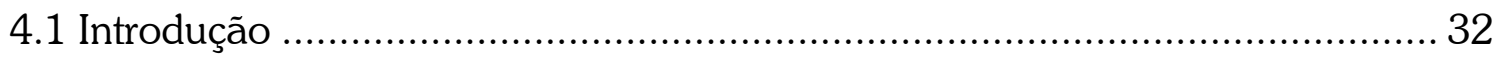

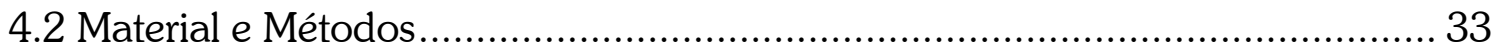

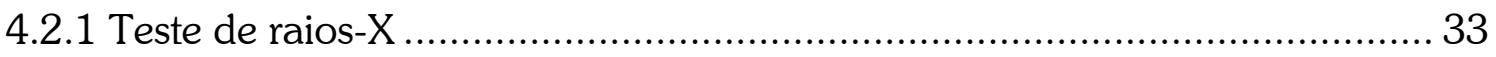

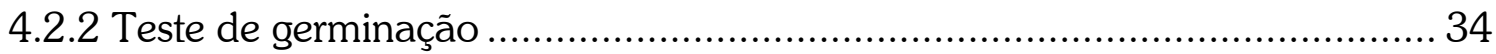

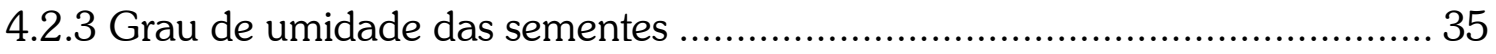

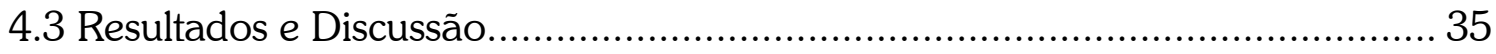

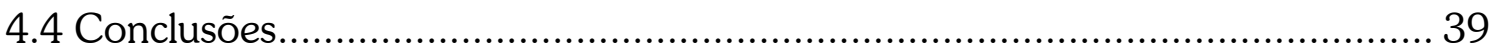

5 CONCLUSÕES

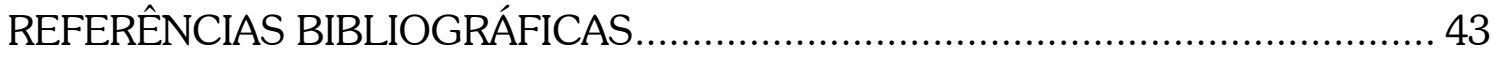




\title{
METODOLOGIA PARA A CONDUÇÃO DO TESTE DE GERMINAÇÃO E UTILIZAÇÃO DE RAIOS-X PARA A AVALIAÇÃO DA QUALIDADE DE SEMENTES DE AROEIRA-BRANCA (Lithraea molleoides (Vell.) Engl.)
}

\author{
Autora: CIBELE FERREIRA MACHADO \\ Orientador: Prof. Dr. SILVIO MOURE CICERO
}

\section{RESUMO}

O presente trabalho foi realizado visando estabelecer metodologia para o teste de germinação e verificar a possibilidade de uso do teste de raios-X para avaliar a qualidade de sementes de aroeira-branca. Foram utilizados quatro lotes de sementes colhidas em áreas da região sul de Minas Gerais, no ano de 2001. As condições de execução do teste de germinação foram determinadas com base nas percentagem e velocidade de germinação das sementes sob nove faixas de temperatura em um gradiente linear entre 15 e $35^{\circ} \mathrm{C}$ e sobre os substratos papel mata-borrão, areia e vermiculita. Para o teste de raios-X, as sementes foram radiografadas e classificadas em função do estádio de desenvolvimento e da morfologia, normal e anormal, dos embriões; após o teste de germinação, procedeu-se a comparação da anatomia das sementes com as respectivas plântulas/sementes resultantes. Os resultados permitiram concluir que: (1) o teste de germinação deve ser conduzido a $27^{\circ} \mathrm{C}$, sobre substrato vermiculita e as contagens efetuadas aos 20 e 45 dias após sua instalação; (2) o teste de raios-X é eficiente na detecção de danos e anormalidades nos embriões prejudiciais à germinação. 


\title{
METHODOLOGY FOR PERFORMING THE GERMINATION TEST AND UTILIZATION OF X-RAYS TO EVALUATE SEED QUALITY OF 'AROEIRA-BRANCA' (Lithraea molleoides (Vell.) Engl.)
}

\author{
Author: CIBELE FERREIRA MACHADO \\ Adviser: Prof. Dr. SILVIO MOURE CICERO
}

\section{SUMMARY}

The present work was carried out with the objective to establish a methodology for the germination test and to verify the possibility to use the X-rays in the evaluation of 'aroeira-branca' seed quality. Four seed lots collected in different places in the south region of the State of Minas Gerais in 2001 were used. The conditions for performing the germination test were determinated basing on the percentage and on the rate of seed germination under nine ranges of temperature in a linear gradient between 15 and $35^{\circ} \mathrm{C}$ and on substrates of blotters, sand and vermiculite. For the X-ray test, radiography of seeds were made as well as classification in relation to stage of development and morphology, normal and abnormal, of embryo; the germination test was run aiming to detect possible relationship between seedlings/seeds and the respective anatomy as revealed by radiographic pictures. It was concluded that the germination test for 'aroeira-branca' seeds may be run at $27^{\circ} \mathrm{C}$ on vermiculite substrate; records have to be made on twenty and forty-five days after the begining of the test. The X-ray test was seen to be able to detect successfully damages and abnormalities in embryos of 'aroeirabranca' seeds. 


\section{INTRODUÇÃO}

A aroeira-branca (Lithraea molleoides (Vell.) Engl. - Anacardiaceae) é uma espécie arbórea que apresenta grande potencial de uso em programas de reflorestamento, devido ao seu pioneirismo e à sua agressividade. Pode ser

empregada na medicina popular e como planta ornamental na arborização de parques e jardins; além disso, a madeira é apropriada para construção civil, marcenaria, lenha e carvão. Multiplica-se por sementes que, a exemplo do que ocorre com outras espécies florestais, têm sido pouco investigadas no que se refere ao controle de qualidade.

A propagação de um grande número de espécies florestais encontra sérias limitações em razão do pouco conhecimento que se dispõe sobre as características fisiológicas, morfológicas e ecológicas de suas sementes. Este cenário representa um entrave em qualquer programa de maior extensão que necessite periodicamente de sementes de alta qualidade para a propagação dessas espécies, visando à preservação e utilização com os mais variados interesses. Em decorrência, torna-se necessário a intensificação de pesquisas visando ao estabelecimento de métodos disponíveis para a avaliação da qualidade de sementes, com ênfase naqueles que envolvem procedimentos padrões, possibilitando a obtenção de resultados comparáveis.

O teste de germinação, incluído nesse contexto, é empregado rotineiramente para avaliar a qualidade das sementes. As informações fornecidas por esse teste são usualmente complementadas pelas de outros, dentre os quais o 
teste de raios-X tem se destacado para as sementes de espécies florestais, por ser um método preciso, rápido e não destrutivo.

Diante do exposto, este trabalho foi proposto com o intuito de estabelecer bases para o controle de qualidade de sementes de aroeira-branca, por meio dos testes de germinação e de raios-X. 


\section{REVISÃO DE LITERATURA}

\subsection{Lithraea molleoides (Vell.) Engl.}

A aroeira-branca, Lithraea molleoides (Vell.) Engl., também conhecida vulgarmente como aroeira-brava, aroeirinha, aroeira-do-brejo, aroeira-da-capoeira e bugreiro, é uma espécie arbórea pertencente à família Anacardiaceae, nativa das regiões sudeste, centro-oeste e sul do Brasil (Lorenzi, 1992; Davide et al., 1995).

É uma espécie de expressão econômica e importância ecológica. Lithraea molleoides fornece madeira dura, compacta e pouco elástica, pópria para construção civil, marcenaria, lenha e carvão; a casca é tanífera e tintorial; as folhas são aromáticas e medicinais; as flores são melíferas; os frutos e as sementes contêm óleos essenciais, com as mesmas aplicações da terebintina (Corrêa, 1926; Coimbra, 1958; Lorenzi, 1992). É empregada ainda como planta ornamental na arborização de parques e jardins (Lorenzi, 1992); porém, a esta espécie são atribuídos efeitos alergênicos aos que se abrigam à sua sombra ou em sua vizinhança e por contatos prolongados com suas estruturas vegetativas e reprodutivas (Corrêa, 1926).

A espécie apresenta dispersão ampla, porém irregular, ocorrendo principalmente em formações secundárias; floresce durante os meses de agosto e setembro, produzindo frutos maduros nos meses de novembro a janeiro (Lorenzi, 1992). Os frutos de Lithraea molleoides são simples, drupáceos-drupa, unispermos; as sementes são unitegumentadas e exalbuminosas; os embriões são do tipo axial curvado ou pleurorrizo, com dois cotilédones planos, eixo hipocótilo-radícula longo e plúmula pouco desenvolvida (Carmello-Guerreiro, 1996). 


\subsection{Teste de germinação}

O processo germinativo compreende aqueles eventos celulares e metabólicos que se iniciam com a absorção de água por sementes quiescentes e culminam com o alongamento do eixo embrionário, conforme enfatizado por Côme \& Tissaoui (1973), Bewley \& Black (1994), Bewley (1997) e Egley (1999).

Em tecnologia de sementes, porém, a conceituação de germinação tem um cunho mais prático, incluindo a fase de crescimento da plântula neste processo. Portanto, a germinação de sementes, em teste de laboratório, é a emergência das estruturas essenciais do embrião, demonstrando sua aptidão para produzir planta normal sob condições favoráveis de campo (Brasil, 1992; ISTA, 1993).

A percentagem de plântulas normais obtida no teste de germinação representa o máximo que a amostra pode oferecer, uma vez que o teste é conduzido sob condições ótimas, artificiais e padronizadas para cada espécie avaliada.

\subsubsection{Condições para a germinação}

Para que a germinação ocorra satisfatoriamente, a semente, viva e não dormente, deve dispor de condições favoráveis de ambiente. Os fatores ambientais essenciais à germinação das sementes são a água, o oxigênio e a temperatura. $\mathrm{O}$ grau de exigência desses fatores é variável entre as espécies e é determinado pelo genótipo e pelas condições ambientais prevalecentes durante a formação das sementes (Mayer \& Poljakoff-Mayber, 1975).

A água é o fator básico determinante do processo germinativo. De acordo com Bewley \& Black (1994), a absorção de água por sementes ortodoxas maduras, trifásica, inicia-se com uma rápida absorção pelos biocolóides, ocorrendo a embebição de todos os seus tecidos (fase I), cuja velocidade é determinada pela composição química da semente, permeabilidade do fruto ou do tegumento da semente à água e disponibilidade de água (Mayer \& Poljakoff-Mayber, 1975; Copeland \& McDonald, 1985). Após a

embebição das sementes, ocorre uma fase de absorção estacionária (fase II) e, em seguida, o restabelecimento da absorção associado com a emergência do eixo 
embrionário (fase III). Portanto, a absorção de água durante a fase de embebição é suficiente para o reinício das atividades metabólicas que culminam com a efetiva retomada de crescimento pelo eixo embrionário (Bewley, 1997).

Adicionalmente, o aumento de volume da semente, resultante da entrada de água em seu interior, provoca a ruptura do tegumento, viabilizando, desse modo, a difusão de oxigênio para os tecidos internos e o início da emergência da raiz primária (Marcos Filho, 1986; Carvalho \& Nakagawa, 2000).

A intensificação da atividade respiratória é uma das alterações iniciais ocorridas a partir da embebição das sementes (Bewley, 1997). A respiração envolve a oxidação de matérias orgânicas na semente com a formação de energia e de substâncias intermediárias necessárias aos processos anabólicos da germinação (Bewley \& Black, 1978; Carvalho \& Nakagawa, 2000). Portanto, o oxigênio é outro fator fundamental para que a germinação ocorra, muito embora, as exigências das sementes com relação à esse elemento sejam usualmente baixas comparando-se com os níveis com que ocorre na atmosfera (Copeland \& McDonald, 1985; Marcos Filho, 1986; Carvalho \& Nakagawa, 2000). Vale salientar que o teor de oxigênio necessário para a germinação aumenta conforme se eleva a temperatura do ambiente e vice-versa (Côme \& Tissaoui, 1973).

Durante o teste de germinação as sementes são supridas de água por absorção através de substratos como papel, pano, areia e solo. O suprimento de oxigênio, por sua vez, é, em grande parte, determinado pela condição de umidade, uma vez que o excesso de água limita a disponibilidade de oxigênio (Pollock, 1974). Adicionalmente, o substrato funciona como um suporte físico para o desenvolvimento das plântulas.

Os substratos citados anteriormente são aqueles indicados nas Regras para Análise de Sementes (Brasil, 1992); entretanto, outros vêm sendo empregados no teste de germinação em sementes de espécies florestais, dos quais a vermiculita tem se destacado por suas características favoráveis à germinação das sementes, tais como alta capacidade de retenção de água e condições adequadas de aeração (Oliveira et al., 1989; Figliolia et al., 1993; Figliolia \& Piña-Rodrigues, 1995; Poulsen et al., 1998).

Dentro de certos limites, quanto maior a área de contato entre a semente e o substrato umedecido, maior a velocidade de absorção de água pelas sementes (Popinigis, 
1977; Marcos Filho, 1986; Carvalho \& Nakagawa, 2000). Existe uma velocidade ótima de absorção de água; quando o processo ocorre lentamente, a germinação é reduzida, provavelmente em decorrência de infecção por fungos ou pela aceleração da deterioração; por outro lado, uma absorção de água muito rápida pode ocasionar danos às sementes (Vertucci, 1989).

De um modo geral, um substrato para ser usado em teste de germinação deve preencher certos requisitos: ser atóxico à semente; ser isento de microrganismos; e manter uma proporção adequada entre a disponibilidade de água e a aeração (Popinigis, 1977; Thomson, 1979; Copeland \& McDonald, 1985).

A escolha do substrato deve ser efetuada em função da espécie a ser analisada e considerando algumas das suas características, tais como o tamanho das sementes, a necessidade de água e luz e a facilidade da contagem e avaliação das plântulas (Marcos Filho et al., 1987; Brasil, 1992).

O fator temperatura, por sua vez, influencia a germinação de forma expressiva, tanto por agir sobre a velocidade de absorção de água, como sobre as reações bioquímicas que determinam todo o processo; afeta, portanto, não só o total de germinação, como também a velocidade do processo (Bewley \& Black, 1994; Carvalho \& Nakagawa, 2000).

A germinação da semente é um processo complexo, compreendendo diversas fases individualmente afetadas pela temperatura (Popinigis, 1977; Copeland \& McDonald, 1985). Nesse sentido, os efeitos da temperatura sobre a germinação refletem apenas a conseqüência global (Mayer \& Poljakoff-Mayber, 1975).

A germinação das sementes ocorre em intervalos de temperatura dentro do qual existe uma temperatura ou faixa de temperaturas na qual o processo ocorre com maior eficiência, ou seja, a máxima germinação no menor período de tempo (Mayer \& Poljakoff-Mayber, 1975; Marcos Filho, 1986; Bewley \& Black, 1994; Carvalho \& Nakagawa, 2000). A temperatura ótima e os limites extremos constituem-se nas temperaturas cardeais para a germinação, variáveis entre as espécies e de acordo com os graus de maturidade e deterioração das sementes (MacKay, 1974; Popinigis, 1977; Mayer \& Poljakoff-Mayber, 1975). 
A temperatura ótima para a germinação de sementes da maioria das espécies está entre 15 e $30^{\circ} \mathrm{C}$, a máxima varia de 30 a $40^{\circ} \mathrm{C}$, podendo a mínima aproximar-se do ponto de congelamento (Copeland \& McDonald, 1985). Com relação às espécies arbóreas tropicais e subtropicais, a germinação de suas sementes tem ocorrido com maior eficiência na faixa de 20 a $30^{\circ} \mathrm{C}$ (Borges \& Rena, 1993).

As temperaturas cardeais para a germinação são definidas em função do período de exposição das sementes (Mayer \& Poljakoff-Mayber, 1975; Carvalho \& Nakagawa, 2000), devido ao fato das diferentes fases do processo serem afetadas pela temperatura (Copeland \& McDonald, 1985).

Dentro de certos limites, acréscimos de temperatura contribuem para acelerar o processo de germinação, enquanto temperaturas abaixo da ótima tendem a reduzir a velocidade do processo (Marcos Filho, 1986; Carvalho \& Nakagawa, 2000).

Existem espécies cujo processo germinativo é favorecido por alternância diária de temperatura; porém, essa necessidade pode estar associada à dormência das sementes, embora a alternância de temperatura possa acelerar a germinação de sementes não dormentes (MacKay, 1974; Thomson, 1979; Copeland \& McDonald, 1985; Mayer, 1986).

Assim, para a condução do teste de germinação temperaturas constantes ou alternadas são indicadas nas Regras para Análise de Sementes (Brasil, 1992; ISTA, 1993) de acordo com a espécie a ser avaliada.

\subsubsection{Metodologia para as espécies florestais}

As Regras para Análise de Sementes (Brasil, 1992) especificam as condições e o período para a condução do teste de germinação em sementes de um grande número de espécies vegetais, das quais as espécies florestais constituem pequena parcela. As Regras para Análise de Sementes da "International Seed Testing Association" (ISTA, 1993), por sua vez, consideram apenas as espécies florestais de clima temperado.

Contudo, a crescente demanda de sementes de espécies florestais, seja com a finalidade econômica como para preservação do meio ambiente, tem determinado a 
intensificação de estudos relacionados ao controle de qualidade das mesmas. Em decorrência, verifica-se, na literatura, um número expressivo de trabalhos visando ao suprimento desta carência, que culminou com a elaboração de proposições que reúnem dados referentes a testes específicos para a análise de sementes dessas espécies, publicados por Piña-Rodrigues \& Vieira (1988), Oliveira et al. (1989) e Figliolia \& Piña-Rodrigues (1995).

Mais recentemente, Poulsen et al. (1998), em publicação da ISTA, elaboraram um manual específico para a análise de sementes de espécies florestais tropicais e subtropicais, incluindo metodologias para a condução do teste de germinação em sementes de diversas espécies.

$\mathrm{Na}$ literatura pertinente ainda são encontrados outros trabalhos indicando as condições de execução do teste de germinação em sementes de espécies florestais. Exemplos de algumas dessas espécies, bem como o substrato, a temperatura, o período e tratamentos para aquelas dormentes, para a condução do teste são: Cedrela odorata (cedro) - sobre papel ou vermiculita; 25 ou $30^{\circ} \mathrm{C} ; 16$ dias (Andrade \& Pereira, 1994); Ocotea corymbosa (canela) - sobre papel; $30^{\circ} \mathrm{C}$; 63 dias (Bilia et al., 1998); Euterpe edulis (palmiteiro) - entre vermiculita; $20-30^{\circ} \mathrm{C}$ ou $25^{\circ} \mathrm{C} ; 98$ dias (Andrade et al., 1999); Machaerium stiptatum (sapuva) - entre papel; $25^{\circ} \mathrm{C} ; 22$ dias e Acacia longifolia (acáciamarítima) - sobre areia; $25^{\circ} \mathrm{C} ; 42$ dias (Medeiros \& Zanon, 1999); Genipa americana (jenipapo) - sobre vermiculita ou solo; 25, 30 ou 35 ${ }^{\circ} \mathrm{C} ; 70$ dias (Andrade et al., 2000); Peltophorum dubium (canafístula) - rolo de papel; $30^{\circ} \mathrm{C} ; 10$ dias; imersão em água a $95^{\circ} \mathrm{C}$ (Oliveira, 2000); e Sebastiania commersoniana (branquilho) - sobre areia; 20$30^{\circ} \mathrm{C} ; 14$ dias (Santos \& Aguiar, 2000).

Relatos sobre metodologia para a condução do teste de germinação em sementes de aroeira-branca não foram encontrados na literatura. 


\subsection{Teste de raios-X}

O teste de raios-X, introduzido por Simak \& Gustafsson (1953) com o intuito de avaliar a qualidade de sementes de algumas coníferas, no âmbito da tecnologia de sementes, consiste na análise radiográfica das estruturas internas de sementes, sendo, atualmente, utilizado para várias finalidades.

O teste baseia-se no princípio da obtenção de imagens com o emprego de raios-X. Assim, ao atravessar as sementes, um feixe de raios- $\mathrm{X}$ cria uma imagem permanente dessas sobre um filme. As imagens podem apresentar maior ou menor grau de radiopacidade (claras) e radioluminescência (escuras) em função do nível de absorção dos raios- $\mathrm{X}$ pelas sementes, determinado pelos fatores composição, espessura e densidade dos tecidos e comprimento de onda da radiação ionizante (Simak, 1980; ISTA, 1993).

Embora os raios- $\mathrm{X}$ sejam potencialmente nocivos às sementes, a baixa dose absorvida durante o teste não causa mutações genéticas nas sementes e não afeta a germinação das mesmas (Simak \& Gustafsson, 1953; Swaminathan \& Kamra, 1961; Chavagnat \& Le Lezec, 1984; Bino et al., 1993). Além disso, trata-se de um teste que não requer tratamento prévio das sementes, o que confere vantagens por ser um método não destrutivo, rápido e de simples execução. Em razão disso, o seu uso tem sido crescente, trazendo benefícios em diferentes etapas da produção e utilização das sementes, incluindo trabalhos de melhoramento genético.

A radiografia das sementes permite a visualização de injúrias mecânicas, danos por insetos e decorrentes de outros fatores adversos pré e pós-colheita, na forma de rachaduras ou fraturas (Simak, 1980; ISTA, 1993; Poulsen et al., 1998); possibilita, ainda, a deteçcão de anormalidades em embriões, bem como a determinação do estádio de desenvolvimento dos mesmos (Simak \& Gustafsson, 1953; Simak, 1980).

Em programas de controle de qualidade de sementes de espécies florestais (Simak \& Gustafsson, 1953; Simak, 1980) e de olerícolas (Chavagnat, 1987) é um método de uso rotineiro. 
A técnica de raios-X pode ser útil em programas de melhoramento de plantas, por permitir o isolamento de embriões mutantes de Arabidopsis thaliana (Bino et al., 1993) e a obtenção de embriões haplóides de melão (Sauton et al., 1989).

O método permite, ainda, determinar a viabilidade de sementes. Nesse caso, o procedimento consiste em impregnar as sementes de agentes de contraste, como metais e água, previamente à radiografia das mesmas (MacKay, 1974; Simak, 1980; Copeland \& McDonald, 1985; Poulsen et al., 1998). O método tem sido adotado na avaliação de sementes de Pinus spp. (Simak, 1970, 1980, 1984; Simak \& Kamra, 1963; Sahlén, 1995), milho (Smith \& Grabe, 1985), algumas cucurbitáceas (kamra, 1964, 1966), entre outras espécies agrícolas e florestais (Swaminathan \& Kamra, 1961).

É um método alternativo para determinar a qualidade de sementes de Pinus sylvestris, Pinus contorta e Picea abies não germinadas durante o período de tempo previsto para o teste em laboratório (Simak, 1980; Simak \& Sahlén, 1981; Simak, 1984; Simak et al., 1989).

A inclusão do teste de raios-X nas Regras para Análise de Sementes (Brasil, 1992; ISTA, 1993) tem como objetivo básico a complementação das informações fornecidas pelo teste de germinação. Para tanto, sementes das amostras destinadas ao teste de germinação são previamente radiografadas e classificadas, de acordo com o perfil anatômico visualizado, em sementes cheias, vazias e danificadas, sendo as duas últimas categorias comumente verificadas em sementes de espécies florestais.

Aspectos morfológicos das sementes, possivelmente associados à viabilidade, podem ser avaliados pelo teste de raios-X (Copeland \& McDonald, 1985). Assim, vários pesquisadores têm procurado relacionar a anatomia das sementes com a germinação ou morfologia das plântulas, cuja correspondência tem variado de acordo com a espécie (Simak, 1991). Dentre as espécies em que se verificou tal correspondência, destacam-se as sementes de tomate (Van der Burg et al., 1994), milho (Cicero et al., 1998; Carvalho et al., 1999; Obando Flor, 2000), Peltophorum dubium - canafístula (Oliveira, 2000) e Cupressus sempervirens - cipreste italiano (Battisti et al., 2000), demonstrando ser esta uma técnica eficiente para predeterminar a germinação de sementes. A morfologia de embriões de maçã - Malus domestica, em contrapartida, não se relacionou com a 
germinação (Bouvier et al., 1992); portanto, sementes anatomicamente 'perfeitas', conforme verificado no teste de raios-X, podem apresentar desempenho ineficiente durante a germinação. Tal fato pode ser verificado em decorrência de condições ambientais desfavoráveis à germinação, da presença de sementes com infecções latentes, sementes mortas por causas naturais, em estádios avançados de deterioração, ou submetidas a um armazenamento inadequado (Swaminathan \& Kamra, 1961; Van der Burg, 1994).

$\mathrm{O}$ teste de raios- $\mathrm{X}$ deve ser executado mediante a determinação prévia das condições de exposição das sementes à radiação. Assim, a qualidade, ou poder de penetração, dos raios-X é determinada pela quilovoltagem do aparelho de raios-X. $\mathrm{O}$ tempo de exposição, juntamente com a miliamperagem fixa do aparelho, regulam a quantidade de raios- $X$, que determina a densidade radiográfica ou grau de escurecimento. Nesse sentido, diferentes interações voltagem/tempo de exposição para a obtenção de imagens radiográficas apuradas de sementes, têm sido adotadas em função da espécie, do aparelho de raios- $X$ e da sensibilidade do filme radiográfico utilizado (Simak, 1980; ISTA, 1993). Na literatura pertinente são encontradas algumas referências sobre as condiçõos de exposição das sementes à radiação para espécies florestais. As sementes de canafístula, por exemplo, foram melhor visualizadas radiograficamente após exposição em um aparelho Faxitron, Hewlett-Packard (modelo 43855A) regulado a $25 \mathrm{kVp} / 60$ segundos (Oliveira, 2000), enquanto o mesmo aparelho de raios-X regulado a $20 \mathrm{kV} / 4$ minutos permitiu a obtenção de imagens radiográficas mais nítidas de sementes de cipreste italiano (Battisti et al., 2000). Por sua vez, a imagem radiográfica de sementes de Acacia auriculiformis, expostas às condições 20 kV/30 segundos com o uso de um aparelho Faxitron, Hewlett-Packard (modelo 43804N), permitiu uma visualização satisfatória de suas estruturas internas (Pukittayacamee \& Hellum, 1988). A condução do teste sob condições controladas o torna um teste reproduzível, conferindo- lhe uma vantagem adicional.

A técnica pode ser empregada com êxito em espécies florestais, cujas sementes comumente apresentam variações no estádio de desenvolvimento do embrião na época de colheita e germinam lentamente, aliados ao beneficiamento das sementes 
ainda deficiente. Além disso, muitas dessas espécies possuem sementes com tegumento duro ou se encerram em frutos com essa característica (Copeland \& McDonald, 1985) que, mesmo após longo período de embebição, tornam sua avaliação inexeqüível por outros métodos. 


\section{METOdOLOGIA PARA A CONDUÇÃO DO TESTE DE GERMINAÇÃO EM SEMENTES DE AROEIRA-BRANCA (Lithraea molleoides (Vell.) Engl.)}

\section{Resumo}

O presente trabalho teve como objetivo determinar a(s) temperatura(s), $\mathrm{o}(\mathrm{s})$ substrato(s) e o período para a condução do teste de germinação em sementes de aroeira-branca. Foram utilizados quatro lotes de sementes colhidas em áreas da região sul de Minas Gerais, no ano de 2001. Foram avaliadas as percentagem e velocidade de germinação das sementes em testes conduzidos sob nove faixas de temperatura em um gradiente linear entre 15 e $35^{\circ} \mathrm{C}$ e sobre os substratos papel mata-borrão, areia e vermiculita. As plântulas normais $e$ as anormalidades manifestadas nos tratamentos foram caracterizadas. De acordo com os resultados foi constatado que as condições favoráveis à germinação das sementes de aroeirabranca são a temperatura de $27^{\circ} \mathrm{C}$ e o substrato vermiculita, sendo que nessas condições as contagens podem ser efetuadas aos 20 e 45 dias após a instalação do teste.

\section{Summary}

This work aimed to determine the proper temperature, substrate and period of time for performing the germination test of 'aroeira-branca' seeds. Four seed lots collected in different places in the south region of the State of Minas Gerais 
in 2001 were used. Percentage and seed germination speed were evaluated under nine ranges of temperature in a linear gradient between 15 and $35^{\circ} \mathrm{C}$ on substrates of blotters, sand and vermiculite. The normal and abnormal seedlings that were formed in the germination test were characterized. According to the results it was seen that temperature of $27^{\circ} \mathrm{C}$ and vermiculite substrate provided the most favourable conditions for germination of 'aroeira-branca' seeds. Evaluation in this test is recommended to be done on twenty and forty-five days following the test setting up.

\subsection{Introdução}

A qualidade das sementes é avaliada rotineiramente em laboratório mediante a condução do teste de germinação. O teste foi desenvolvido $e$ aperfeiçoado visando à determinação do valor das sementes para a semeadura e à comparação da qualidade de diferentes lotes, servindo como base para a comercialização das sementes (MacKay, 1974; Popinigis, 1977; Marcos Filho et al., 1987).

O teste de germinação determina a percentagem de sementes capazes de germinar normalmente, com base nas características morfológicas das plântulas. É conduzido sob condições ótimas e padronizadas para cada espécie avaliada.

As Regras para Análise de Sementes, tanto nacionais como internacionais, indicam o substrato, a temperatura, os limites de tempo e, no caso de sementes dormentes, luz ou outros tratamentos especiais para a condução do teste.

A intensidade da resposta das sementes ao ambiente é variável entre as espécies; assim, as condições de execução do teste são estabelecidas nas Regras para Análise de Sementes para um grande número de espécies vegetais, das quais as espécies florestais constituem pequena parcela (Brasil, 1992). 
A aroeira-branca multiplica-se por sementes as quais têm tido limitações no que se refere à disponibilidade de metodologia para avaliar o potencial germinativo. Os estudos sobre a germinação de sementes de aroeira-branca são praticamente inexistentes, e, segundo Davide et al. (1995), as sementes não requerem tratamento pré-germinativo.

Diante do exposto, o objetivo do presente trabalho foi determinar a(s) temperatura(s), o(s) substrato(s) e o período para a condução do teste de germinação em sementes de aroeira-branca.

\subsection{Material e Métodos}

A pesquisa foi conduzida nos Laboratórios de Análise de Imagens e de Análise de Sementes, do Departamento de Produção Vegetal, da Escola Superior de Agricultura "Luiz de Queiroz"/Universidade de São Paulo, em Piracicaba/SP.

\subsubsection{Colheita e preparo das sementes}

A colheita de frutos foi realizada em janeiro de 2001, em áreas distintas de ocorrência natural da espécie, na região sul de Minas Gerais $\left(21^{\circ} 04^{\prime}-21^{\circ} 14^{\prime}\right.$ S; $45^{\circ} 02^{\prime}-45^{\circ} 12^{\prime} \mathrm{W}$ ), nos municípios de ljaci (lote 1), de Lavras (lotes 2 e 3) e de Ribeirão Vermelho (lote 4).

Foram colhidos, manualmente, frutos maduros de diferentes matrizes por área. Após a colheita, os frutos, tipo drupa, foram submetidos à fricção manual em peneira sob água corrente para a remoção do epicarpo. Em seguida, procedeu-se a secagem dos frutos (sem epicarpo), doravante denominados 'sementes' (Figura 1a), em sala climatizada $\left(20^{\circ} \mathrm{C} ; 55 \% \mathrm{UR}\right)$, onde permaneceram por vinte dias (Carvalho, 2000), ocasião em que atingiram o grau de umidade de equilíbrio em torno de $10 \%$. 
Durante o período experimental, as sementes, acondicionadas em embalagens de papel, permaneceram em câmara regulada a $19 \pm 1^{\circ} \mathrm{C}$ e $50 \pm 8 \%$ UR.

\subsubsection{Experimento 1: efeito da temperatura na germinação das sementes}

Os testes de germinação foram conduzidos em uma mesa termogradiente (Van den Berg, modelo 890.5), sob nove faixas de temperaturas distribuídas em um gradiente linear entre 15 e $35^{\circ} \mathrm{C}$, com 8 horas de luz/dia.

Foram empregadas 25 sementes/repetição/lote previamente desinfestadas por imersão em solução de hipoclorito de sódio (2\%), por 3 minutos, com posterior lavagem com água destilada. As sementes foram distribuídas em placas de Petri de $9 \mathrm{~cm}$ de diâmetro (25 sementes/placa) sobre duas folhas de papel mata-borrão previamente esterilizadas, em estufa a $105^{\circ} \mathrm{C} / 2$ horas (Brasil, 1992), e umedecidas com água destilada (volume de água equivalente a 2,5 vezes o seu peso sem hidratação). As placas foram vedadas com parafilm e os substratos foram mantidos úmidos no transcorrer dos testes.

As avaliações foram efetuadas diariamente por um período de 60 dias após a instalação dos testes. Os resultados foram expressos em percentagem de germinação (Brasil, 1992) e velocidade de germinação, determinada pelo tempo (dias) para a obtenção de $50 \%$ do potencial germinativo dos lotes (T50\%), conforme relatado por Copeland \& McDonald (1985) e Bewley \& Black (1994), e pelo índice de velocidade de germinação (IVG), proposto por Maguire (1962):

$$
\begin{gathered}
\text { IVG }=\frac{G_{1}}{N_{1}}+\frac{G_{2}}{N_{2}}+\ldots+\frac{G_{n}}{N_{n}} \text {, em que: } \\
G_{1}+G_{2}+\ldots+G_{n}=\text { número de plântulas normais computadas na }
\end{gathered}
$$
primeira, segunda, ..., e última contagens, respectivamente;

$\mathrm{N}_{1}+\mathrm{N}_{2}+\ldots+\mathrm{N}_{\mathrm{n}}$ = número de dias decorridos da semeadura à primeira, segunda, ..., e última contagens, respectivamente. 
A interpretação do teste foi efetuada com base nos critérios gerais estabelecidos nas Regras para Análise de Sementes (Brasil, 1992), sendo que as plântulas normais $e$ as anormalidades manifestadas foram caracterizadas $e$ fotodocumentadas por uma câmera digital Nikon, modelo D1.

O grau de umidade das sementes foi determinado, previamente à execução do experimento, pelo método de estufa a $105 \pm 3^{\circ} \mathrm{C} / 24$ horas (Brasil, 1992). Os resultados, expressos em percentagem, foram calculados com base no peso úmido $(\mathrm{Bu})$.

\subsubsection{Análise estatística}

Os experimentos, referentes às nove temperaturas, foram instalados em delineamento inteiramente casualizado, com quatro lotes e quatro repetições. Foi realizada a análise conjunta dos experimentos. Os dados de germinação foram transformados em arco seno $(\mathrm{x} / 100)^{0,5}$. A comparação das médias foi realizada pelo teste de Tukey a $5 \%$ de probabilidade.

\subsubsection{Experimento 2: avaliação de substratos}

Os testes de germinação foram conduzidos em câmara de germinação (Marconi, modelo MA 401) regulada a $27^{\circ} \mathrm{C}$, com 8 horas de luz/dia. As sementes foram previamente desinfestadas, conforme procedimento descrito no item 3.2.2, e, em seguida, foram distribuídas em caixas plásticas, tipo gerbox, com dimensões de $11,0 \times 11,0 \times 3,0 \mathrm{~cm},(25$ sementes/caixa) contendo os substratos papel mataborrão, areia e vermiculita.

Quanto ao substrato papel mata-borrão, as sementes foram distribuídas sobre duas folhas previamente esterilizadas, em estufa a $105^{\circ} \mathrm{C} / 2$ horas (Brasil, 1992), e umedecidas com água destilada (volume de água equivalente a 2,5 vezes o seu peso sem hidratação). 
Com relação ao substrato areia, as sementes foram distribuídas sobre uma camada de $2 \mathrm{~cm}$ do mesmo. A areia foi previamente peneirada $(0,25-0,50 \mathrm{~mm} \varnothing)$, lavada, esterilizada em estufa a $200^{\circ} \mathrm{C} / 2$ horas (Brasil, 1992) e umedecida com água destilada a $60 \%$ da capacidade de retenção.

No terceiro substrato testado, vermiculita, as sementes foram distribuídas sobre uma camada de $2 \mathrm{~cm}$ deste $(0,6-1,2 \mathrm{~mm} \varnothing)$ previamente umedecido com água destilada a $60 \%$ da capacidade de retenção.

Os substratos foram mantidos úmidos no decorrer dos testes. As avaliações, efetuadas diariamente por um período de 50 dias após a instalação dos testes, constituíram os resultados expressos em percentagem de germinação (Brasil, 1992) e velocidade de germinação, conforme descrito no item 3.2.2.

$\mathrm{O}$ grau de umidade das sementes foi determinado, previamente à execução do experimento, pelo método de estufa a $105 \pm 3^{\circ} \mathrm{C} / 24$ horas (Brasil, 1992). Os resultados, expressos em percentagem, foram calculados com base no peso úmido $(\mathrm{Bu})$.

\subsubsection{Análise estatística}

O experimento foi instalado no delineamento inteiramente casualizado, em esquema fatorial $4 \times 3$ (4 lotes e 3 substratos), com oito repetições; os dados de germinação foram transformados em arco seno $(\mathrm{x} / 100)^{0,5}$. A comparação das médias foi realizada pelo teste de Tukey a $5 \%$ de probabilidade.

\subsection{Resultados e Discussão}

\subsubsection{Experimento 1: efeito da temperatura na germinação das sementes}

As sementes dos quatro lotes de aroeira-branca apresentaram graus de umidade em torno de $10 \%$, por ocasião da instalação dos testes de germinação. 
O resumo das análises de variância conjuntas das avaliações efetuadas nos testes de germinação conduzidos sob diferentes temperaturas é apresentado na Tabela 1. Verifica-se a detecção de diferença significativa $(\mathrm{P}<0,01)$ entre os lotes, entre as temperaturas e na interação lote $\times$ temperatura, para todos os caracteres avaliados.

Tabela 1. Resumo das análises de variância conjuntas da germinação $(G)$, do índice de velocidade de germinação (IVG) e do tempo para a obtenção de $50 \%$ do potencial germinativo (T50\%) de lotes de sementes de aroeira-branca sob diferentes temperaturas.

\begin{tabular}{lcccc}
\hline \multirow{2}{*}{$\begin{array}{c}\text { Fontes de } \\
\text { Variação }\end{array}$} & \multirow{2}{*}{ G.L. } & \multicolumn{3}{c}{ Quadrados Médios } \\
\cline { 3 - 5 } & & $\mathrm{G}$ & $\mathrm{IVG}$ & $\mathrm{T} 50 \%$ \\
\hline Lote & 3 & $1415,889^{* *}$ & $0,463^{* *}$ & $434,564^{* *}$ \\
Temperatura & 8 & $1400,793^{* *}$ & $1,374^{* *}$ & $475,053^{* *}$ \\
Lote $\times$ Temperatura & 24 & $203,348^{* *}$ & $0,135^{* *}$ & $94,278^{* *}$ \\
Resíduo & 108 & 26,466 & 0,010 & 20,428 \\
C.V. (\%) & & 10,21 & 13,06 & 18,13 \\
\hline **: significativo a 1\% de probabilidade pelo teste F.
\end{tabular}

De acordo com os resultados apresentados na Tabela 2, verifica-se que a temperatura ótima para o total de germinação das sementes, comum aos quatro lotes, está na faixa de 23,2 a $27,4^{\circ} \mathrm{C}$, sendo que a amplitude dessa faixa foi variável entre os lotes.

É sabido que as sementes mais vigorosas germinam sob ampla faixa de temperatura, ao passo que sementes mais deterioradas são pouco tolerantes aos desvios do nível ótimo (Marcos Filho, 1986; Carvalho \& Nakagawa, 2000). Nesse aspecto, o desempenho superior do lote 2 permitiu a expressão do potencial de germinação de suas sementes sob a faixa de 18,5 a $29,7^{\circ} \mathrm{C}$ (Tabela 2). 
Tabela 2. Germinação de sementes de lotes de aroeira-branca: valores médios (\%) obtidos nos testes de germinação conduzidos sob diferentes temperaturas.

\begin{tabular}{ccccc}
\hline Temperatura & \multicolumn{5}{c}{ Lote } \\
\cline { 2 - 5 } média $\left({ }^{\circ} \mathbf{C}\right)$ & $\mathbf{1}$ & $\mathbf{2}$ & $\mathbf{3}$ & $\mathbf{4}$ \\
\hline 16,3 & $25 \mathrm{c}^{1}$ & $69 \mathrm{~b}$ & $15 \mathrm{c}$ & $25 \mathrm{~d}$ \\
18,5 & $43 \mathrm{bc}$ & $76 \mathrm{ab}$ & $37 \mathrm{~b}$ & $37 \mathrm{~cd}$ \\
20,6 & $55 \mathrm{ab}$ & $81 \mathrm{ab}$ & $58 \mathrm{a}$ & $56 \mathrm{bc}$ \\
23,2 & $64 \mathrm{a}$ & $90 \mathrm{a}$ & $57 \mathrm{a}$ & $82 \mathrm{a}$ \\
25,3 & $71 \mathrm{a}$ & $85 \mathrm{ab}$ & $65 \mathrm{a}$ & $78 \mathrm{a}$ \\
27,4 & $69 \mathrm{a}$ & $85 \mathrm{ab}$ & $66 \mathrm{a}$ & $77 \mathrm{a}$ \\
29,7 & $57 \mathrm{ab}$ & $85 \mathrm{ab}$ & $44 \mathrm{~b}$ & $65 \mathrm{~b}$ \\
31,6 & $42 \mathrm{bc}$ & $44 \mathrm{c}$ & $41 \mathrm{~b}$ & $56 \mathrm{bc}$ \\
33,7 & $40 \mathrm{bc}$ & $32 \mathrm{c}$ & $37 \mathrm{~b}$ & $45 \mathrm{c}$ \\
\hline
\end{tabular}

${ }^{1}$ Médias seguidas de mesma letra na coluna não diferem entre si, pelo teste de Tukey, a 5\% de probabilidade.

De acordo com os índices de velocidade de germinação das sementes (Tabela 3), verifica-se que a temperatura ótima para a velocidade do processo foi variável entre os lotes ocorrendo na faixa de 27,4 a $31,6^{\circ} \mathrm{C}$.

Os dados referentes ao tempo gasto para a obtenção de $50 \%$ do potencial germinativo dos lotes (Tabela 4) permitem verificar que, na faixa de 23,2 a $27,4^{\circ} \mathrm{C}$, em que se observou percentagens superiores de germinação (Tabela 2), não foi detectada diferença entre a velocidade do processo germinativo. 
Tabela 3. Índice de velocidade de germinação de sementes de lotes de aroeirabranca: valores médios obtidos nos testes de germinação conduzidos sob diferentes temperaturas.

\begin{tabular}{ccccc}
\hline Temperatura & \multicolumn{4}{c}{ Lote } \\
\cline { 2 - 5 } média $\left({ }^{\circ} \mathbf{C}\right)$ & $\mathbf{1}$ & $\mathbf{2}$ & $\mathbf{3}$ & $\mathbf{4}$ \\
\hline 16,3 & $0,30 \mathrm{e}^{1}$ & $0,43 \mathrm{~d}$ & $0,15 \mathrm{e}$ & $0,21 \mathrm{e}$ \\
18,5 & $0,56 \mathrm{~d}$ & $0,72 \mathrm{c}$ & $0,28 \mathrm{de}$ & $0,45 \mathrm{~d}$ \\
20,6 & $0,67 \mathrm{~d}$ & $0,75 \mathrm{c}$ & $0,51 \mathrm{~cd}$ & $0,54 \mathrm{~d}$ \\
23,2 & $0,69 \mathrm{~d}$ & $0,85 \mathrm{bc}$ & $0,55 \mathrm{c}$ & $0,78 \mathrm{c}$ \\
25,3 & $0,92 \mathrm{c}$ & $0,90 \mathrm{bc}$ & $0,78 \mathrm{bc}$ & $0,96 \mathrm{bc}$ \\
27,4 & $0,94 \mathrm{c}$ & $1,07 \mathrm{~b}$ & $1,12 \mathrm{a}$ & $1,40 \mathrm{a}$ \\
29,7 & $1,22 \mathrm{~b}$ & $1,48 \mathrm{a}$ & $0,81 \mathrm{~b}$ & $1,03 \mathrm{~b}$ \\
31,6 & $1,62 \mathrm{a}$ & $0,90 \mathrm{bc}$ & $0,80 \mathrm{~b}$ & $0,93 \mathrm{bc}$ \\
33,7 & $0,77 \mathrm{~cd}$ & $0,76 \mathrm{c}$ & $0,83 \mathrm{~b}$ & $0,85 \mathrm{bc}$ \\
\hline
\end{tabular}

${ }^{1}$ Médias seguidas de mesma letra na coluna não diferem entre si, pelo teste de Tukey, a 5\% de probabilidade.

Tabela 4. Tempo para a obtenção de $50 \%$ do potencial germinativo de lotes de sementes de aroeira-branca: valores médios (dias) obtidos nos testes de germinação conduzidos sob diferentes temperaturas.

\begin{tabular}{ccccc}
\hline Temperatura & \multicolumn{4}{c}{ Lote } \\
\cline { 2 - 5 } média $\left({ }^{\circ} \mathbf{C}\right)$ & $\mathbf{1}$ & $\mathbf{2}$ & $\mathbf{3}$ & $\mathbf{4}$ \\
\hline 16,3 & $29,4 \mathrm{a}^{1}$ & $40,0 \mathrm{a}$ & $36,3 \mathrm{a}$ & $36,5 \mathrm{a}$ \\
18,5 & $26,9 \mathrm{ab}$ & $32,7 \mathrm{ab}$ & $34,5 \mathrm{ab}$ & $33,2 \mathrm{ab}$ \\
20,6 & $26,1 \mathrm{abc}$ & $25,6 \mathrm{bc}$ & $33,1 \mathrm{ab}$ & $31,4 \mathrm{abc}$ \\
23,2 & $21,0 \mathrm{abc}$ & $24,7 \mathrm{bc}$ & $26,6 \mathrm{abc}$ & $28,0 \mathrm{abcd}$ \\
25,3 & $23,1 \mathrm{abc}$ & $18,4 \mathrm{~cd}$ & $25,5 \mathrm{bc}$ & $26,4 \mathrm{bcd}$ \\
27,4 & $20,9 \mathrm{abc}$ & $16,3 \mathrm{~cd}$ & $25,2 \mathrm{bc}$ & $24,5 \mathrm{bcd}$ \\
29,7 & $17,7 \mathrm{bc}$ & $16,3 \mathrm{~cd}$ & $27,4 \mathrm{abc}$ & $27,0 \mathrm{abcd}$ \\
31,6 & $16,1 \mathrm{c}$ & $13,3 \mathrm{~d}$ & $21,3 \mathrm{c}$ & $22,7 \mathrm{~cd}$ \\
33,7 & $16,4 \mathrm{c}$ & $10,2 \mathrm{~d}$ & $17,5 \mathrm{c}$ & $18,2 \mathrm{~d}$ \\
\hline
\end{tabular}

${ }^{1}$ Médias seguidas de mesma letra na coluna não diferem entre si, pelo teste de Tukey, a 5\% de probabilidade. 
A queda do poder germinativo verificada nas temperaturas médias inferiores a $23,2^{\circ} \mathrm{C}$, possivelmente decorreu do declínio da velocidade do processo, uma vez que o tempo prolongado para o início da germinação favoreceu o desenvolvimento de microrganismos visivelmente verificados nas sementes. Nas mesmas condições foi constada, ainda, a ocorrência de plântulas com tamanho reduzido (Figura 2d) em relação às obtidas nas demais temperaturas. $\mathrm{O}$ comportamento germinativo das sementes nessas condições correspondeu ao relatado por Marcos Filho (1986) e Carvalho \& Nakagawa (2000), ao se referirem às sementes cujo processo de embebição ocorre sob temperaturas abaixo da ótima.

Por outro lado, as temperaturas acima da ótima proporcionam aumento na velocidade de germinação, mas provocam desorganização do processo de sorte que o número de sementes que conseguem completá-lo vai caindo rapidamente, em decorrência, basicamente, dos efeitos sobre a atividade de enzimas e das restrições ao acesso de oxigênio (Côme \& Tissaoui, 1973; Marcos Filho, 1986).

Assim, as temperaturas superiores a $27,4^{\circ} \mathrm{C}$, embora tenham acelerado o processo germinativo das sementes, provocaram um aumento na incidência de plântulas anormais, confirmado pelo diagnóstico sanitário; a taxa de emissão da raiz primária se manteve elevada, porém, o desenvolvimento subseqüente da plântula foi prejudicado, resultando na deterioração de seus tecidos, conforme ilustrado na Figura $2 e-f$.

Portanto, as temperaturas fora da faixa de 23,2 a $27,4^{\circ} \mathrm{C}$ se traduziram na queda da percentagem de plântulas normais e, ou, na morte das sementes.

$\mathrm{Na}$ prática, a determinação das condições de execução do teste, adequadas à germinação das sementes de uma determinada espécie, baseia-se na combinação de fatores ambientais que resulta numa germinação mais regular, rápida e completa para a maioria de suas amostras (MacKay, 1974).

Desse modo, com base nos resultados obtidos e nas avaliações dos testes, verifica-se que a temperatura ótima para a germinação das sementes dos lotes de 
aroeira-branca utilizados neste trabalho está em torno de $27,4^{\circ} \mathrm{C}$, uma vez que com essa temperatura é alcançada a máxima percentagem de germinação no menor tempo. Resultados semelhantes foram obtidos para outras espécies, dentre as quais destacam-se: Prosopis juliflora (Sw.) DC. - algarobeira (Perez \& Moraes, 1990); Stryphnodendron polyphyllum Mart. (Tambelini \& Perez, 1999); e Pterogyne nitens Tul. - amendoim-do-campo (Nassif \& Perez, 2000).

A interpretação dos testes de germinação foi efetuada com base nos critérios gerais estabelecidos nas Regras para Análise de Sementes (Brasil, 1992). As sementes de aroeira-branca apresentam germinação epígea, porém o epicótilo e a plúmula não se desenvolveram durante o período de realização dos testes sob as diferentes temperaturas; assim, foram consideradas, na avaliação, as plântulas com os cotilédones emersos do fruto. As plântulas originadas na faixa ótima de temperatura atingiram esse estádio a partir do terceiro dia após a instalação dos testes, sendo a germinação distribuída ao longo de aproximadamente 50 dias.

Conforme enfatizam as Regras para Análise de Sementes (Brasil, 1992), as plântulas normais demonstram ser aptas à produção de plantas normais sob condições favoráveis de campo. As plântulas normais de aroeira-branca originadas nos testes foram basicamente as seguintes: plântulas intactas, com os cotilédones, hipocótilo e raiz primária, apresentando ou não raízes secundárias, bem desenvolvidos e sadios (Figura 1b) e plântulas com pequenos defeitos, apresentando raiz primária com o desenvolvimento deficiente, porém com raízes secundárias bem desenvolvidas (Figura 1c).

As plântulas anormais, por sua vez, são aquelas que não apresentam potencial para originar plântulas normais sob condições favoráveis de campo. Assim, as anormalidades manifestadas nas plântulas originadas na faixa ótima de temperatura foram: plântulas com deformações e coloração atípica, apresentando tecido bastante rijo (Figura 2a), anormalidade essa manifestada apenas no lote 2; 
plântulas com sistema radicular ausente (Figura 2b); plântulas com os tecidos deteriorados (Figura 2c).

Com relação às sementes não germinadas no teste de germinação, essas são classificadas em sementes mortas, duras, dormentes e outras, incluindo as sementes vazias e danificadas (Brasil, 1992). As classes em questão são discriminadas por meio de testes complementares aos de germinação, como os de raios-X, de tetrazólio e de cortes de sementes. Vale salientar, porém, que a unidade de propagação de aroeira-branca é um fruto tipo drupa e, portanto, inviabiliza a execução de testes cujos métodos exigem o corte das sementes para o exame do embrião. Nesse sentido, o teste de raios-X é o mais apropriado para uso em análise de sementes desta espécie. As aplicações do teste de raios-X em sementes de aroeira-branca são abordadas no item 4 . 


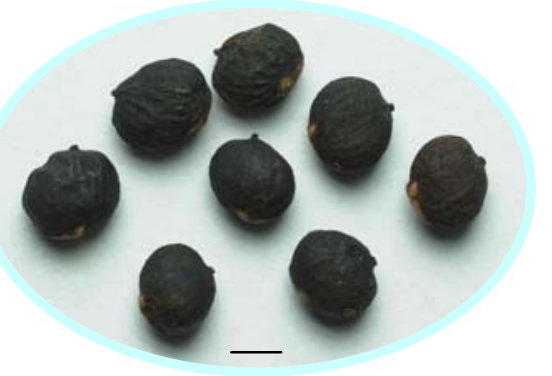

(a)

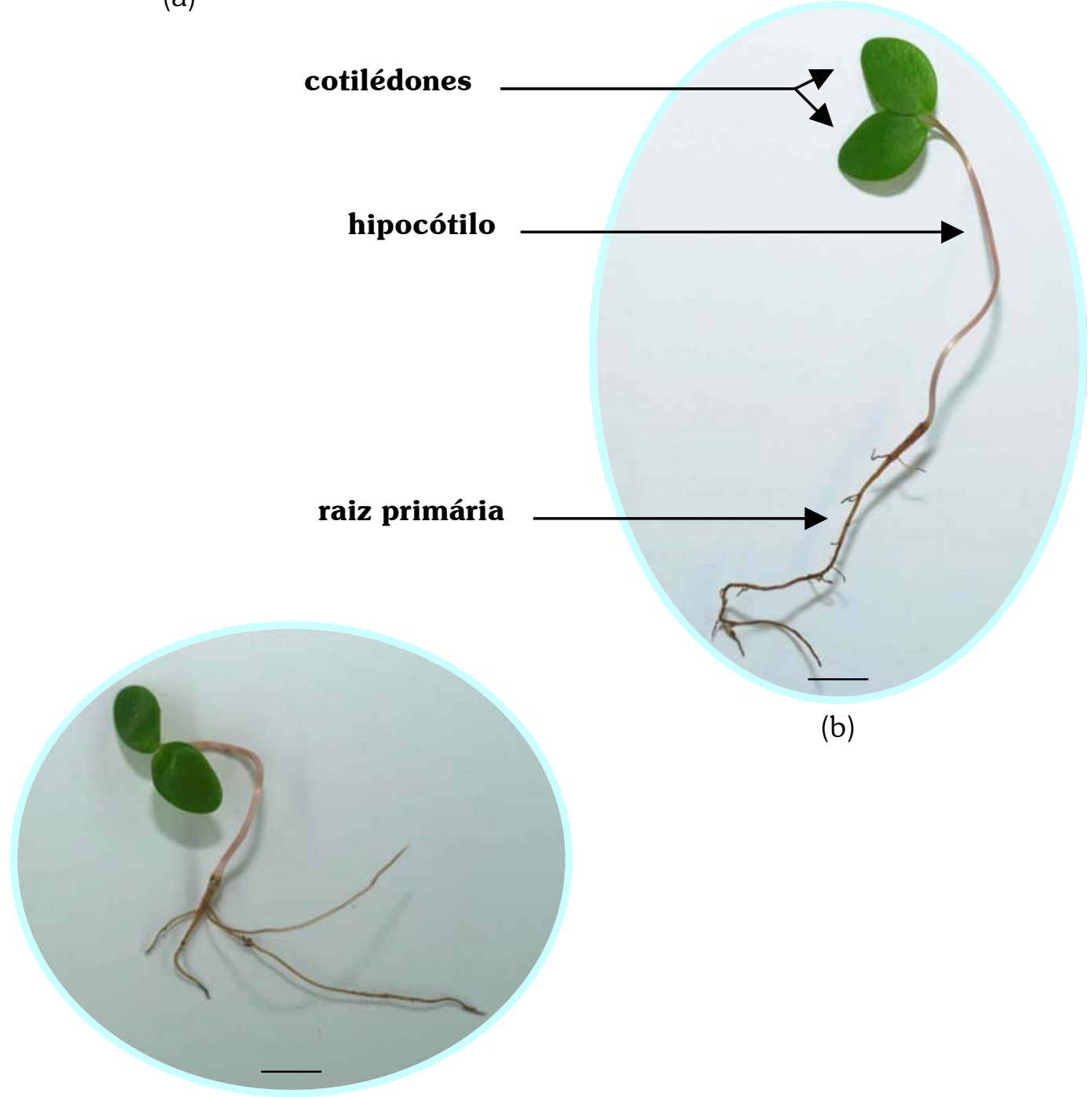

(c)

Figura 1- Aroeira-branca: (a) unidade de propagação (barra $=2,3 \times 10^{-3} \mathrm{~m}$ ); (b) plântula normal intacta (barra $=5,9 \times 10^{-3} \mathrm{~m}$ ); (c) plântula normal com pequeno defeito (barra $=5,8 \times 10^{-3} \mathrm{~m}$ ). 


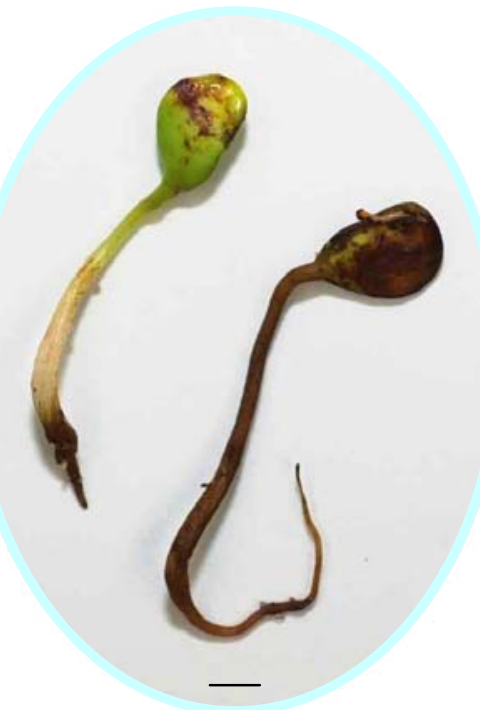

(a)

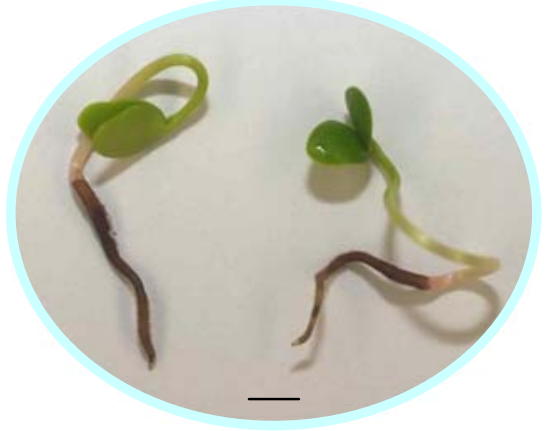

(d)

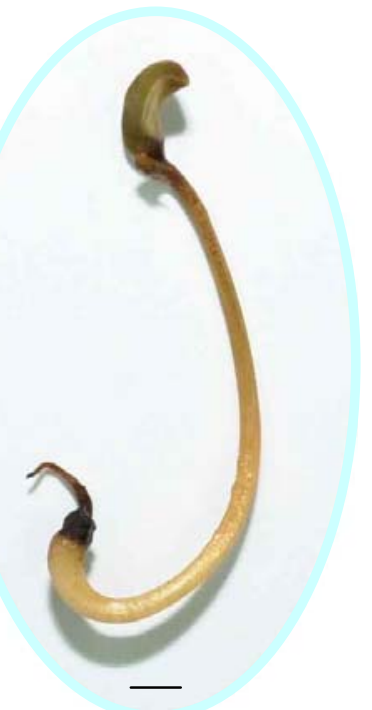

(b)

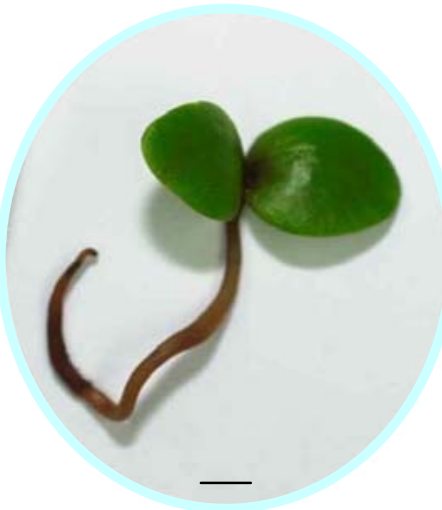

(e)

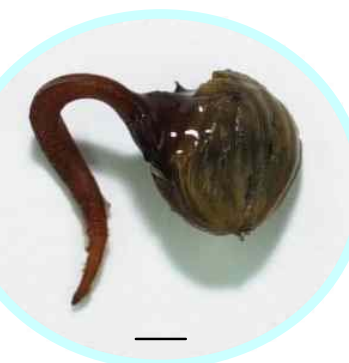

(c)

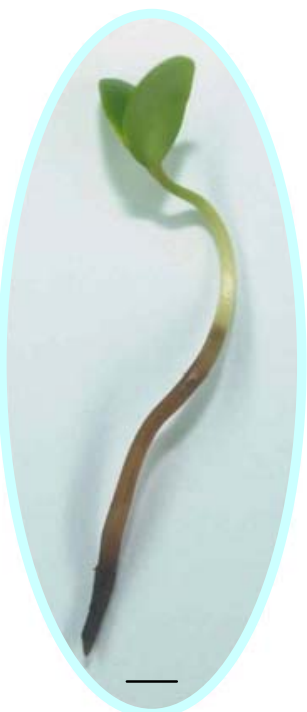

(f)

Figura 2- Plântulas anormais de aroeira-branca: (a) com deformações (barra $=3,9 \times$ $10^{-3} \mathrm{~m}$ ), (b) com o sistema radicular ausente (barra $=1,9 \times 10^{-3} \mathrm{~m}$ ), (c) com os tecidos deteriorados (barra $=1,5 \times 10^{-3} \mathrm{~m}$ ); plântulas com anormalidades decorrentes de estresse térmico: (d) tamanho reduzido (barra $\left.=3,1 \times 10^{-3} \mathrm{~m}\right),(e-\mathrm{f})$ hipocótilo e raiz primária deteriorados (barra (e) $=2,1 \times 10^{-3} \mathrm{~m}$; barra (f) $=2,3 \times 10^{-3} \mathrm{~m}$ ). 


\subsubsection{Experimento 2: avaliação de substratos}

As sementes dos quatro lotes de aroeira-branca apresentaram graus de umidade em torno de 9,5\%, por ocasião da instalação do experimento.

O resumo das análises de variância das avaliações efetuadas nos testes de germinação conduzidos em diferentes substratos é apresentado na Tabela 5. Verifica-se a detecção de diferença significativa entre os lotes $(\mathrm{P}<0,01)$, entre os substratos, apenas com relação à velocidade de germinação das sementes (IVG: $\mathrm{P}<0,01 ;$ T50\%: $\mathrm{P}<0,05)$, não havendo efeito da interação lote $\times$ substrato.

Tabela 5. Resumo das análises de variância da germinação (G), do índice de velocidade de germinação (IVG) e do tempo para a obtenção de $50 \%$ do potencial germinativo (T50\%) de lotes de sementes de aroeirabranca em diferentes substratos.

\begin{tabular}{|c|c|c|c|c|}
\hline \multirow{2}{*}{$\begin{array}{l}\text { Fontes de } \\
\text { Variação }\end{array}$} & \multirow{2}{*}{ G.L. } & \multicolumn{3}{|c|}{ Quadrados Médios } \\
\hline & & G & IVG & T50\% \\
\hline Lote & 3 & $2170,500^{* *}$ & $0,498 * *$ & $410,578 * *$ \\
\hline Substrato & 2 & $36,919^{\text {ns }}$ & $0,085 * *$ & $82,004 *$ \\
\hline Lote $\times$ Substrato & 6 & $52,168^{\text {ns }}$ & $0,023^{\mathrm{ns}}$ & $13,129^{\text {ns }}$ \\
\hline Resíduo & 84 & 42,457 & 0,017 & 17,203 \\
\hline C.V. (\%) & & 11,76 & 15,99 & 14,59 \\
\hline
\end{tabular}

De acordo com os dados apresentados na Tabela 6, verifica-se que as percentagens de germinação das sementes foram semelhantes nos três substratos testados. Por outro lado, o índice de velocidade de germinação (IVG), bem como o período demandado para a ocorrência de $50 \%$ de germinação (T50\%), no substrato areia, não diferiram estatisticamente daqueles verificados nos substratos 
vermiculita e papel; porém, nessas avaliações foi observada velocidade de germinação das sementes superior no substrato vermiculita em relação ao papel.

Tabela 6. Germinação (G), índice de velocidade de germinação (IVG) e tempo para a obtenção de $50 \%$ do potencial germinativo (T50\%) de quatro lotes de sementes de aroeira-branca: valores médios obtidos nos testes de germinação conduzidos em diferentes substratos.

\begin{tabular}{lccc}
\hline \multicolumn{1}{c}{ Substrato } & G (\%) & IVG & T50\% (dias) \\
\hline Vermiculita & $70 \mathrm{a}^{1}$ & $0,8600 \mathrm{a}$ & $27,11 \mathrm{~b}$ \\
Areia & $67 \mathrm{a}$ & $0,8344 \mathrm{ab}$ & $27,99 \mathrm{ab}$ \\
Papel & $67 \mathrm{a}$ & $0,7606 \mathrm{~b}$ & $30,21 \mathrm{a}$ \\
\hline
\end{tabular}

${ }^{1}$ Médias seguidas de mesma letra na coluna não diferem entre si, pelo teste de Tukey, a $5 \%$ de probabilidade.

É importante salientar que, dentro de certos limites, a velocidade de germinação será tanto maior quanto maior for a velocidade de absorção de água pelas sementes, determinada, dentre outros fatores, pela área superficial de contato entre a semente e o substrato umedecido (Popinigis, 1977; Marcos Filho, 1986; Carvalho \& Nakagawa, 2000). Nesse sentido, a superioridade dos substratos vermiculita e areia com relação à velocidade de germinação, provavelmente deveuse à área de contato entre as sementes e os mesmos, uma vez que as sementes de aroeira-branca apresentam um formato esférico. Embora os substratos vermiculita e areia não tenham diferido entre si, a retenção de água no substrato areia foi inferior, exigindo reposição freqüente de água no transcorrer do teste; fato, este, agravado ainda mais com o uso de substrato papel. Vale ressaltar que a germinação de sementes de aroeira-branca se processa num período relativamente longo.

Foi observado ainda no substrato papel um maior índice de ocorrência de fungos; portanto, outra possível explicação para o desempenho germinativo 
relativamente inferior das sementes com relação à velocidade, refere-se à liberação de lixiviados das sementes nesse meio, os quais não possuem restrição de fluxo podendo atingir as sementes vizinhas, e, assim, favorecer a ocorrência de contaminações secundárias; ao passo que, nos substratos vermiculita e areia os lixiviados se restringem às proximidades das respectivas sementes $e$, ainda, se deslocam para a porção inferior da camada desses substratos.

É importante salientar que o substrato vermiculita permitiu um desenvolvimento das plântulas mais satisfatório, constatado pelo sistema radicular das mesmas, fato também relatado por Figliolia et al. (1993); em decorrência, as avaliações se tornam mais rápidas e seguras.

Embora não seja indicado nas Regras para Análise de Sementes (Brasil, 1992; ISTA, 1993), o substrato vermiculita é empregado rotineiramente em testes de germinação com sementes de espécies florestais, devido às vantagens que proporciona (Oliveira et al., 1989; Figliolia et al., 1993; Figliolia \& Piña-Rodrigues, 1995), também verificadas neste trabalho. Exemplos de algumas espécies florestais, cuja germinação das sementes foi favorecida por este substrato, são: Cedrela odorata L. - cedro (Andrade \& Pereira, 1994); Colubrina glandulosa Perk. saguaraji (Albuquerque et al., 1998); Euterpe edulis Mart. - palmiteiro (Andrade et al., 1999); Genipa americana L. - jenipapo (Andrade et al., 2000).

Os resultados obtidos no presente trabalho, em adição às observações efetuadas no decorrer dos testes, evidenciaram a superioridade do substrato vermiculita, dentre as alternativas avaliadas, sendo o mais conveniente para uso no teste de germinação de sementes de aroeira-branca.

A condução do teste de germinação em sementes de aroeira-branca a $27^{\circ} \mathrm{C}$, sobre substrato vermiculita, permite que as contagens sejam efetuadas aos 20 e 45 dias após a instalação. Tendo em vista que o processo de germinação das sementes é prolongado, é conveniente a realização de contagens intermediárias, conforme enfatizado nas Regras para Análise de Sementes (Brasil, 1992). 


\subsection{Conclusões}

- As condições favoráveis à germinação das sementes de aroeira-branca são a temperatura de $27^{\circ} \mathrm{C}$ e o substrato vermiculita, sendo que nessas condições as contagens do teste podem ser efetuadas aos 20 e 45 dias após sua instalação. 


\section{UTILIZAÇÃO DO TESTE DE RAIOS-X PARA A AVALIAÇÃO DA QUALIDADE DE SEMENTES DE AROEIRA-BRANCA (Lithraea molleoides (Vell.) Engl.)}

\section{Resumo}

O presente trabalho foi realizado com o objetivo de verificar a possibilidade de uso do teste de raios-X na detecção de danos e, ou, anormalidades em embriões de aroeira-branca, bem como o efeito dos mesmos na germinação. Foram empregados os quatro lotes de sementes utilizados na pesquisa anterior. Assim, 100 sementes/lote foram submetidas ao teste de raios-X que consistiu na radiografia (condições de exposição à radiação: $13 \mathrm{kV} / 5$ minutos) e classificação das sementes em proporção embrião/cavidade embrionária de $0,<50,50-75$ e $100 \%$, sendo a última classe dividida quanto à morfologia do embrião, em normal e anormal. Em seguida, foi conduzido o teste de germinação das sementes, visando detectar possíveis correspondências entre a anatomia das sementes e as respectivas plântulas/sementes resultantes. Com base nos resultados, verificou-se que as sementes em que a proporção embrião/cavidade embrionária era inferior a $100 \%$ não germinaram $e$ aquelas pertencentes à classe radiográfica de embrióes morfologicamente anormais resultaram em plântulas anormais ou sementes não germinadas, evidenciando a eficiência da técnica de raios-X para avaliar a qualidade das sementes de aroeira-branca. 


\section{Summary}

The objective of this work was to verify the possibility of using the X-ray test in the detection of damages and embryo abnormalities in 'aroeira-branca' seeds and their effects on seed germination. Seed lots used in this work were the same of the previous experiment. The X-ray test consisted in submitting 100 seeds/lot to radiography (exposure of seeds to radiation of $13 \mathrm{kV} / 5$ minutes) and classification according to embryo/embryonic cavity proportion of $0,<50,50-75$ and $100 \%$, the later divided in normal and abnormal embryo according to morphology. The germination test was run aiming to detect possible relationship between seedlings/seeds and the respective anatomy as revealed by radiographic pictures. Based on the results of this study, it was verified that seeds presenting embryo/ embryonic cavity proportion lower than $100 \%$, as determined by X-ray test, did not germinated and those presenting abnormal embryos produced abnormal seedlings or did not germinated. As conclusion, the X-ray test is able to estimate the quality of 'aroeira-branca' seed lots successfully.

\subsection{Introdução}

A produção de mudas de espécies florestais requer o uso de sementes de alta qualidade, uma vez que falhas na emergência ou a formação de plântulas fracas podem causar sérios prejuízos aos viveiristas ou acréscimos no custo de produção, principalmente quando se trata de semeadura direta em embalagens. Assim, o controle de qualidade de sementes para esse fim deve ser estabelecido com o uso de testes rápidos e precisos como o teste de raios-X, já de uso rotineiro e consagrado para algumas espécies no setor florestal.

O teste de raios-X, por meio da análise radiográfica das estruturas internas de sementes, permite a detecção de danoos e anormalidades em embriões que podem prejudicar a germinação das sementes. A baixa dose de radiação absorvida 
pelas sementes durante o teste confere uma vantagem de ser esse um método não destrutivo, fornecendo, portanto, informações adicionais sobre a viabilidade das mesmas. Nessa circunstância, sementes da amostra destinada ao teste de germinação são previamente radiografadas e classificadas, de acordo com o perfil morfológico visualizado.

A aplicação desta técnica é especialmente promissora em análise de sementes de aroeira-branca, espécie de grande importância econômica e ecológica, cuja unidade de propagação, um fruto tipo drupa, inviabiliza a execução de outros métodos para a avaliação da qualidade de sementes que se baseiam no exame do embrião; adicionalmente, a aroeira-branca dispõe de um período prolongado para a germinação de suas sementes. Neste contexto, o objetivo do presente trabalho foi verificar a possibilidade de uso do teste de raios-X na detecção de danos e, ou, anormalidades em embriões de aroeira-branca, bem como o efeito dos mesmos na germinação.

\subsection{Material e Métodos}

O experimento foi conduzido nos Laboratórios de Análise de Imagens e de Análise de Sementes, do Departamento de Produção Vegetal, da Escola Superior de Agricultura "Luiz de Queiroz"/Universidade de São Paulo, em Piracicaba/SP.

Os lotes de sementes de aroeira-branca empregados consistiram daqueles utilizados na pesquisa anterior (ver item 3.2.1).

\subsubsection{Teste de raios- $\mathrm{X}$}

Para a investigação, foram utilizadas 100 sementes/lote distribuídas em uma placa de acrílico com células individualizadas. Durante a exposição, a placa foi sobreposta ao filme radiográfico (Kodak, Min-R 2000, tamanho de $18 \times 24 \mathrm{~cm}$ ), 
distado $35 \mathrm{~cm}$ da fonte emissora da radiação, usando um aparelho de raios-X Faxitron, Hewlett-Packard (modelo MX-20) regulado a $13 \mathrm{kV}$ e tempo de exposição de 5 minutos. As condições de exposição foram determinadas em ensaios prévios.

Os filmes radiográficos foram revelados em processadora automática (Hope X-Ray, modelo 319 micro-Max) e as imagens radiográficas foram digitalizadas por um scanner (Umax, modelo Power Look 1100), para posterior avaliação das sementes em um computador Pentium III $(600 \mathrm{MHz}$, memória de 256 Mb, HD Ultra SCSI de 20 Gb e monitor de 21").

A análise radiográfica das sementes baseou-se nos diferentes estádios de desenvolvimento do embrião, estabelecidos de acordo com a proporção embrião/cavidade embrionária, de 0, <50, 50-75 e 100\%. As sementes com proporção embrião/cavidade embrionária de $100 \%$ foram ainda divididas em classes quanto à morfologia do embrião, em normal e anormal.

Foram considerados normais os embriões intactos, ou seja, completos $e$ com as estruturas desenvolvidas, e aqueles com danos limitados (com mais de 50\% dos cotilédones funcionais); não foram admitidos danos presentes no eixo embrionário dos embrióes. Vale salientar que as sementes maduras de aroeirabranca apresentam a plúmula pouco desenvolvida, não visível macroscopicamente (Figura 3c) e, por conseguinte, não distinguível na radiografia.

A terminologia, bem como a classificação das sementes, basearam-se naquelas descritas por Simak \& Gustafsson (1953) e Simak (1980) para sementes exalbuminosas de espécies florestais.

\subsubsection{Teste de germinação}

As sementes foram submetidas ao teste de germinação, mantendo-se a identidade de cada uma, para verificação de possíveis correspondências entre a anatomia das sementes e as respectivas plântulas/sementes resultantes. 
O teste foi conduzido em câmara de germinação (Marconi, modelo MA 401) regulada a $27^{\circ} \mathrm{C}$ com 8 horas de luz/dia. As sementes foram prévia e individualmente desinfestadas por imersão em solução de hipoclorito de sódio (2\%), por 3 minutos, com posterior lavagem com água destilada; em seguida, foram distribuídas em caixas plásticas "gerbox" (16 sementes/caixa) sobre uma camada de $2 \mathrm{~cm}$ de vermiculita $(0,6-1,2 \mathrm{~mm} \varnothing)$ previamente umedecida com água destilada (60\% da capacidade de retenção). Os substratos foram mantidos úmidos no transcorrer do teste. As avaliações foram efetuadas diariamente por um período de 45 dias após a instalação do teste.

As condições de execução e a interpretação do teste foram estabelecidas de acordo com os critérios determinados no item 3.

As plântulas originadas, bem como as sementes não germinadas durante o período de tempo previsto para o teste, foram fotodocumentadas por uma câmera digital Nikon, modelo D1, acoplada ao computador descrito no item 4.2.1.

\subsubsection{Grau de umidade das sementes}

Foi determinado, previamente à execução do experimento, pelo método de estufa a $105 \pm 3^{\circ} \mathrm{C} / 24$ horas (Brasil, 1992). Os resultados, expressos em percentagem, foram calculados com base no peso úmido $(\mathrm{Bu})$.

\subsection{Resultados e Discussão}

As sementes de aroeira-branca dos quatro lotes apresentaram graus de umidade em torno de $10 \%$, por ocasião da instalação do experimento.

Com base nas ilustrações da semente e do embrião maduros de aroeirabranca (Figura 3a-b), ficou evidente que a imagem radiográfica das sementes permitiu uma visualização satisfatória de suas estruturas internas (Figuras 4 e 5). 
Assim, a análise radiográfica possibilitou a classificação das sementes de aroeirabranca em função do estádio de desenvolvimento e da morfologia dos embriões.

Os padrões de anormalidade morfológica em embriões de aroeira-branca, verificados na radiografia, foram basicamente os seguintes: danos ocupando mais de $50 \%$ dos cotilédones (Figura $5 e$ ) e, ou, ocorrentes no eixo hipocótilo-radícula (Figura 5d); deformações ou distúrbios morfológicos caracterizados, radiograficamente, pela conformação irregular (Figura 5f).

A freqüência observada dos diferentes estádios de desenvolvimento do embrião identificados nos quatro lotes, bem como das classes quanto à morfologia do embrião em normal e anormal, são apresentados na Tabela 7.

Tabela 7. Percentagem de sementes de aroeira-branca, por lote, verificada nas classes determinadas no teste de raios-X.

\begin{tabular}{|c|c|c|c|c|c|}
\hline \multirow{3}{*}{ Lote } & \multicolumn{5}{|c|}{ Proporção embrião/cavidade embrionária (\%) } \\
\hline & \multirow{2}{*}{$\mathbf{0}$} & \multirow{2}{*}{$<\mathbf{5 0}$} & \multirow{2}{*}{ 50-75 } & \multicolumn{2}{|c|}{100} \\
\hline & & & & Normal & Anormal \\
\hline 1 & 10 & 2 & 3 & 78 & 7 \\
\hline 2 & 1 & 1 & 0 & 82 & 16 \\
\hline 3 & 9 & 5 & 4 & 69 & 13 \\
\hline 4 & 6 & 3 & 0 & 87 & 4 \\
\hline
\end{tabular}

O conjunto de tonalidades claras e escuras observado em imagens radiográficas de sementes é definido em função do nível de absorção dos raios-X em regiões distintas nas sementes que é determinado pela espessura, densidade $e$ composição dos tecidos (Simak, 1980; ISTA, 1993). Assim, sementes de aroeirabranca destituídas de tecidos embrionários, por não apresentarem resistência à passagem dos raios-X, fornecem imagens radiolúcidas (escuras), como mostra a Figura 5a; o que se verifica são apenas canais resiníferos presentes no mesocarpo do fruto e o tegumento da semente. Por outro lado, sementes em que a proporção 
embrião/cavidade embrionária é de $100 \%$ apresentam essa resistência e, portanto, fornecem imagens radiopacas (claras), conforme Figura 4a.

A radiografia das sementes pode auxiliar na avaliação da viabilidade das mesmas (Swaminathan \& Kamra, 1961; Copeland \& McDonald, 1985); para tanto, é necessário o estabelecimento de relações entre as estruturas internas das sementes $e$ as respectivas plântulas resultantes, tal como foi realizado no presente trabalho.

De um modo geral, os resultados obtidos no teste de germinação se corresponderam à germinação prevista em função das classes obtidas com a radiografia das sementes (Tabela 8 ).

Tabela 8. Plântulas normais (PN), plântulas anormais (PA) e sementes não germinadas (SNG), em percentagem, obtidas no teste de germinação dos quatro lotes de sementes de aroeira-branca, em cada classe determinada no teste de raios-X.

\begin{tabular}{|c|c|c|c|c|c|c|c|}
\hline \multirow{3}{*}{ Lote } & \multirow{3}{*}{ Categoria } & \multicolumn{5}{|c|}{ Proporção embrião/cavidade embrionária (\%) } & \multirow{3}{*}{ Total } \\
\hline & & \multirow{2}{*}{$\mathbf{0}$} & \multirow{2}{*}{$<\mathbf{5 0}$} & \multirow{2}{*}{ 50-75 } & \multicolumn{2}{|c|}{100} & \\
\hline & & & & & Normal & Anormal & \\
\hline \multirow[t]{3}{*}{1} & PN & 0 & 0 & 0 & 61 & 0 & 61 \\
\hline & PA & 0 & 0 & 0 & 1 & 0 & 1 \\
\hline & SNG & 10 & 2 & 3 & 16 & 7 & 38 \\
\hline \multirow[t]{3}{*}{2} & PN & 0 & 0 & 0 & 78 & 0 & 78 \\
\hline & PA & 0 & 0 & 0 & 2 & 13 & 15 \\
\hline & SNG & 1 & 1 & 0 & 2 & 3 & 7 \\
\hline \multirow[t]{3}{*}{3} & PN & 0 & 0 & 0 & 64 & 0 & 64 \\
\hline & PA & 0 & 0 & 0 & 1 & 1 & 2 \\
\hline & SNG & 9 & 5 & 4 & 4 & 12 & 34 \\
\hline \multirow[t]{3}{*}{4} & PN & 0 & 0 & 0 & 78 & 0 & 78 \\
\hline & PA & 0 & 0 & 0 & 2 & 0 & 2 \\
\hline & SNG & 6 & 3 & 0 & 7 & 4 & 20 \\
\hline
\end{tabular}


Assim, o teste de germinação revelou a inviabilidade das sementes em que o embrião não apresentou um bom contato com a superfície interna do tegumento em toda sua extensão, visto que, invariavelmente, todas as sementes com proporção embrião/cavidade embrionária inferior a $100 \%$ não germinaram.

A variação no estádio de desenvolvimento do embrião, observada nas amostras de sementes de aroeira-branca, ocorre com freqüência em espécies florestais, certamente devido à maturação desuniforme de suas sementes. Conseqüentemente, durante a época de colheita as árvores apresentam sementes em diferentes estádios de maturidade, ocasião em que se verifica a ocorrência de embriões imaturos morfologicamente. Tal fato determinou o desenvolvimento da técnica de raios-X que, em princípio, visou estabelecer um estádio de desenvolvimento do embrião adequado à colheita (Simak \& Gustafsson, 1953).

Com relação ao perfil morfológico de embriões desenvolvidos (proporção embrião/cavidade embrionária de $100 \%$ ), foi constatado (Tabela 8) que aqueles considerados normais pelo teste de raios-X resultaram em plântulas, normais $e$ anormais, e sementes não germinadas. Contudo, o percentual de plântulas normais originadas/lote, a partir dessa classe, foi: 78,21\% (lote 1); 95,12\% (lote2); 92,75\% (lote 3); 89,66\% (lote 4). Portanto, verifica-se uma boa correspondência entre os mesmos.

Vale ressaltar que durante o teste de germinação as sementes permanecem expostas a fatores que competem para a redução do potencial germinativo, tais como a ação de microrganismos que podem acompanhar as sementes no lote e a presença de sementes mortas por causas naturais ou em estádios mais avançados de deterioração (Swaminathan \& Kamra, 1961; Van der Burg, 1994). Nesse contexto, a qualidade das sementes morfologicamente normais inferida apenas por meio do exame radiográfico das mesmas pode ser questionável.

Por outro lado, os resultados do teste de germinação (Tabela 8) permitiram verificar que as sementes correspondentes às classes de embrióes 
morfologicamente anormais, determinadas no teste de raios-X, originaram apenas plântulas anormais e sementes não germinadas, das quais algumas comprovadamente mortas, segundo o aspecto evidenciado pela abertura dos frutos (Figura 5g). Assim, os embriões da referida classe pertencentes aos lotes 1 e 4 não germinaram, ao passo que, no lote 3 , a germinação de uma semente com o eixo danificado não foi impedida, porém culminou com a formação de uma plântula anormal (Figura 4c). O lote 2, por sua vez, apresentou um número considerável de plântulas anormais, sendo essas originadas de embriões com um distúrbio morfológico característico (Figura 4b). Vale salientar que as plântulas em questão também manifestaram o mesmo padrão de anormalidade, já caracterizado no item 3. Nesse caso particular, a morfologia dos embriões se relacionou com a morfologia das respectivas plântulas originadas no teste de germinação.

Neste trabalho ficou evidente, portanto, que a técnica de raios-X é

eficiente na detecção de danos $e$ anormalidades nos embrióes prejudiciais à germinação das sementes. Desse modo, o descarte de sementes com baixo 'potencial anatômico', tal como determinado nesta pesquisa, pode assegurar um bom desempenho germinativo dos lotes. Este procedimento, quando efetuado previamente à semeadura, se adequa mais em plantas perenes como as espécies florestais.

\subsection{Conclusões}

- O teste de raios-X é eficiente na detecção de danos e anormalidades em embriões de aroeira-branca que afetam negativamente a germinação. 


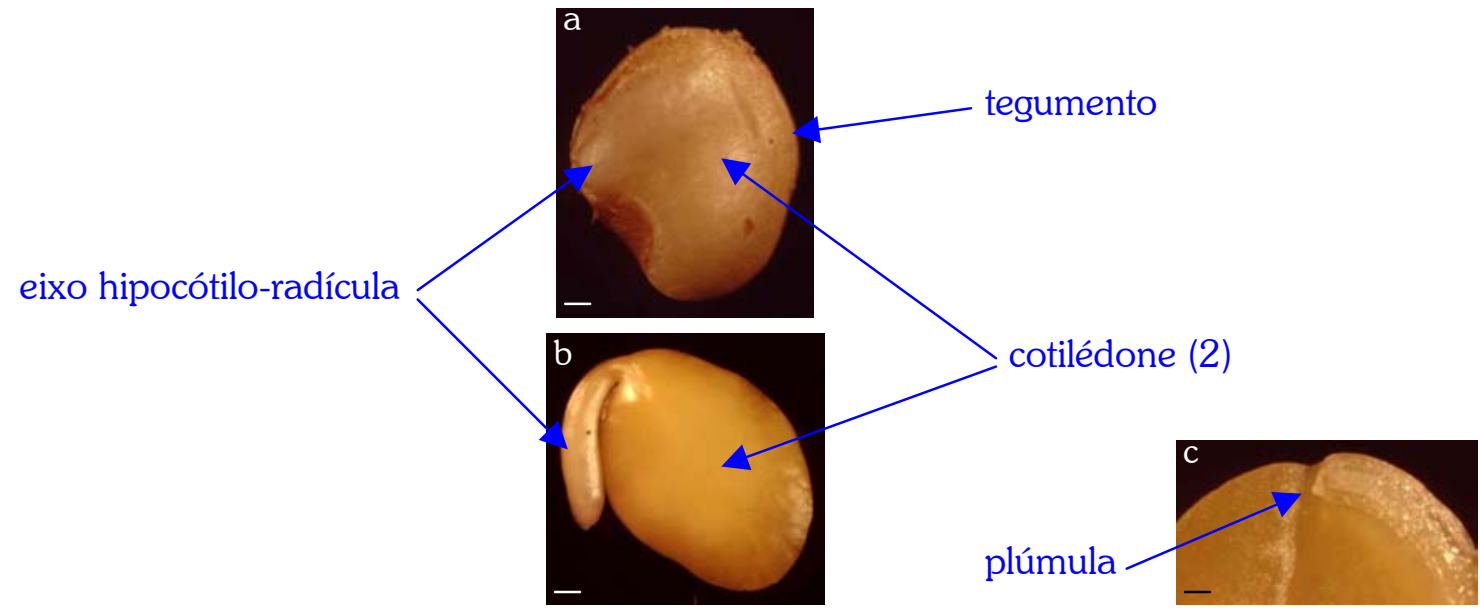

Figura 3- Semente madura de aroeira-branca: (a) aspecto externo; (b) embrião; (c) porção do embrião, secionado longitudinalmente, evidenciando a plúmula. Barra $(\mathrm{a}-\mathrm{b})=$ $4,5 \times 10^{-4} \mathrm{~m}$; barra $(\mathrm{c})=2,2 \times 10^{-4} \mathrm{~m}$.

(a)
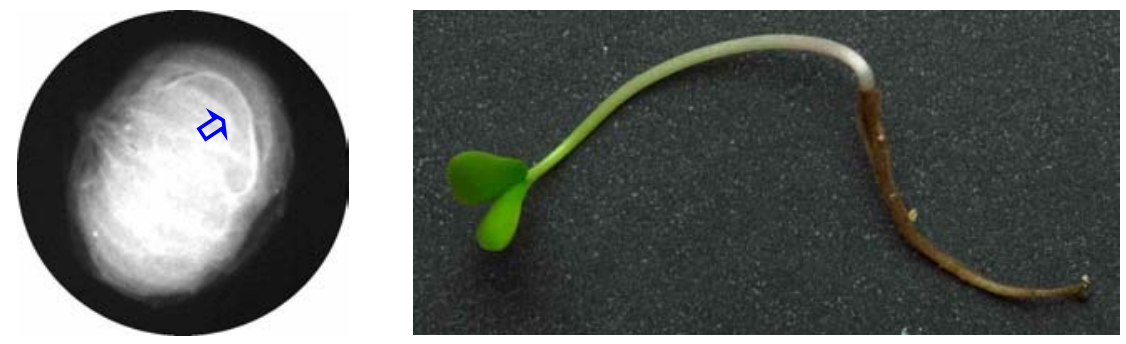

(b)
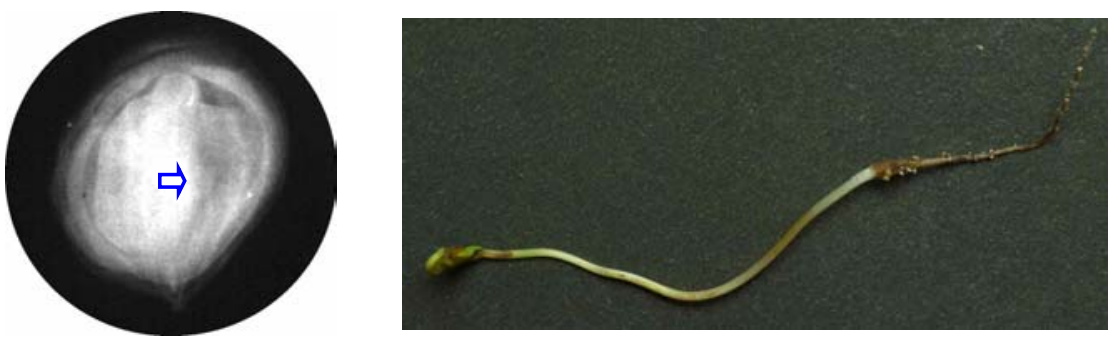

(c)
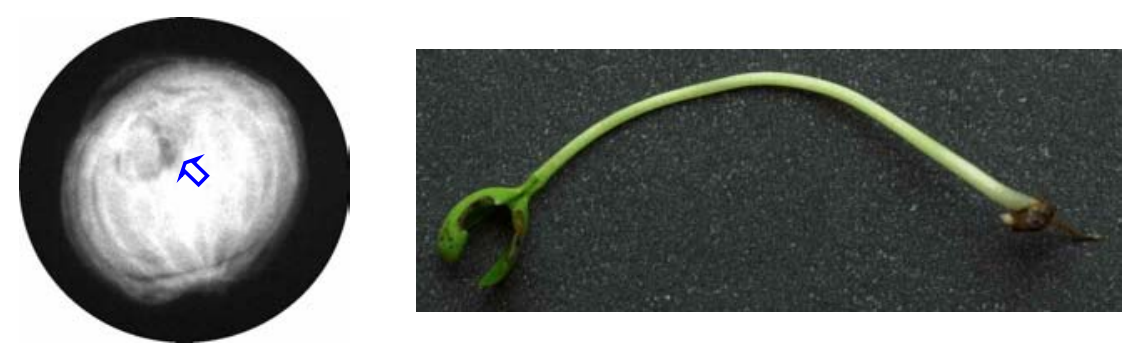

Figura 4- Imagens radiográficas de sementes de aroeira-branca com as respectivas plântulas resultantes: (a) embrião morfologicamente normal e plântula normal (seta indica eixo embrionário); (b) embrião morfologicamente anormal e plântula anormal (seta indica anormalidade); (c) embrião danificado nos cotilédones e no eixo embrionário e plântula anormal (seta indica dano). 


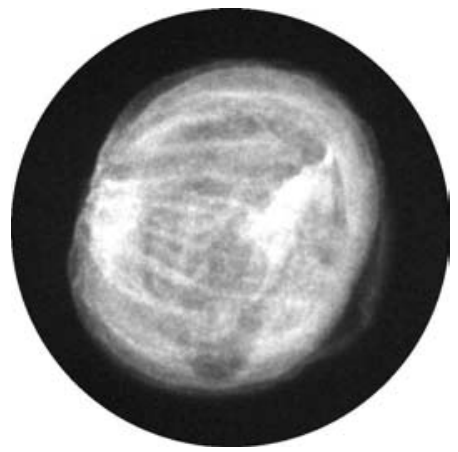

(a)

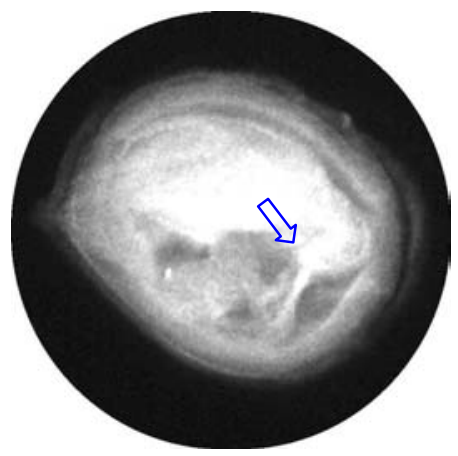

(d)

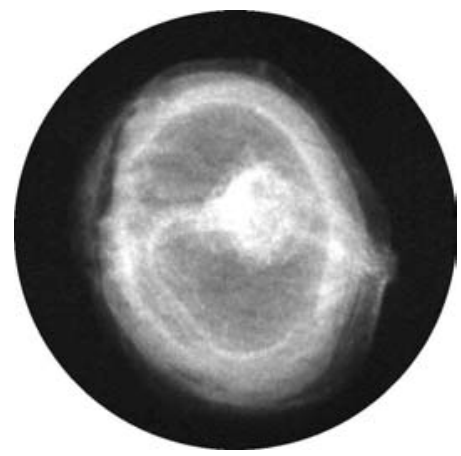

(b)

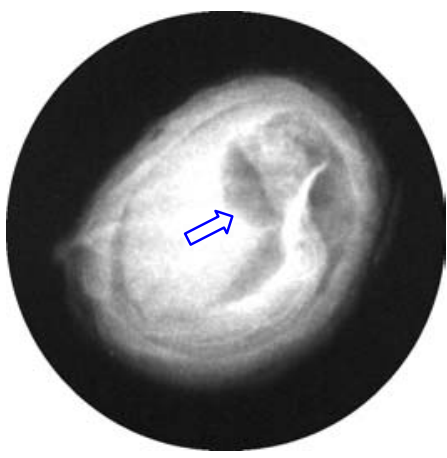

(e)

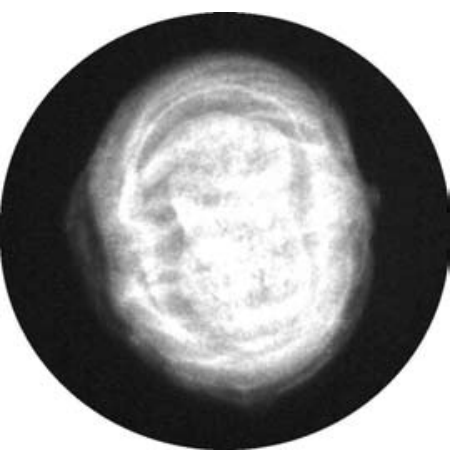

(c)

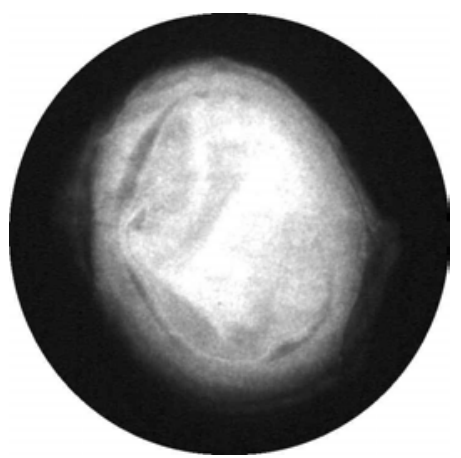

(f)

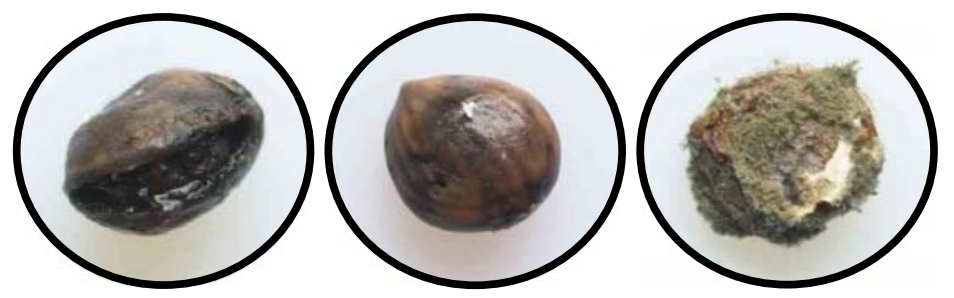

(g)

(h)

(i)

Figura 5- Imagens radiográficas de semente de aroeira-branca: proporções embrião/cavidade embrionária de $0 \%$ (a), < 50\% (b) e 50-75\% (c); embriões com eixo danificado (d), com mais de $50 \%$ dos cotilédones danificados (e) e deformado (f). Aspecto do fruto de sementes de aroeira-branca, não germinadas no teste de germinação, pertencentes às classes de 'a' a 'f' (g-i). 


\section{CONCLUSÕES}

- O teste de germinação em sementes de aroeira-branca deve ser conduzido à temperatura de $27^{\circ} \mathrm{C}$, sobre substrato vermiculita e as contagens efetuadas aos 20 e 45 dias após sua instalação.

- A técnica de raios-X permite a detecção de danos e anormalidades em embriões de aroeira-branca prejudiciais à germinação. 


\section{REFERÊNCIAS BIBLIOGRÁFICAS}

ALBUQUERQUE, M.C.F.; RODRIGUES, T.J.D.; MINOHARA, L.; TEBALDI, N.D.; SILVA, L.M.M. Influência da temperatura e do substrato na germinação de sementes de saguaraji (Colubrina glandulosa Perk. - Rhamnaceae). Revista Brasileira de Sementes, v.20, n.2, p.346-349, 1998.

ANDRADE, A.C.S. de; PEREIRA, T.S. Efeito do substrato e da temperatura na germinação e no vigor de sementes de cedro - Cedrela odorata L. (Meliaceae). Revista Brasileira de Sementes, v.16, n.1, p.34-40, 1994.

ANDRADE, A.C.S. de.; SOUZA, A.F. de; RAMOS, F.N.; PEREIRA, T.S.; CRUZ, A.P.M. Germinação de sementes de jenipapo: temperatura, substrato $e$ morfologia do desenvolvimento pós-seminal. Pesquisa Agropecuária Brasileira, v.35, n.3, p.609-615, 2000.

ANDRADE, A.C.S. de; LOUREIRO, M.B.; SOUZA, A.D.O.; RAMOS, F.N.; CRUZ, A.P.M. Reavaliação do efeito do substrato e da temperatura na germinação de sementes de palmiteiro (Euterpe edulis Mart.). Revista Árvore, v.23, n.3, p.279-283, 1999.

ANDRADE, A.C.S. de; SOUZA, A.F. de; RAMOS, F.N.; PEREIRA, T.S.; CRUZ, A.P.M. Germinação de sementes de jenipapo: temperatura, substrato $e$ morfologia do desenvolvimento pós-seminal. Pesquisa Agropecuária Brasileira, v.35, n.3, p.609-615, 2000. 
BATTISTI, A.; CANTINI, R.; FECI, E.; FRIGIMELICA, G.; GUIDO, M.; ROQUES, A. Detection and evaluation of seed damage of cypress, Cupressus sempervirens L., in Italy. Seed Science and Technology, v.28, n.3, p.729$738,2000$.

BEWLEY, J.D. Seed germination and dormancy. The Plant Cell, v.9, n.7, p.1055-1066, 1997.

BEWLEY, J.D.; BLACK, M. Seeds: physiology of development and germination. 2.ed. New York: Plenum Press, 1994. 445p.

BILIA, D.A.C.; BARBEDO, C.J.; MALUF, A.M. Germinação de diásporos de canela (Ocotea corymbosa (Meissn.) Mez - Lauraceae) em função da temperatura, do substrato e da dormência. Revista Brasileira de Sementes, v.20, n.1, p.189-194, 1998.

BINO, R.J.; AARTSE, J.W.; VAN DER BURG, W.J. Non-destructive X-ray analysis of Arabidopsis embryo mutants. Seed Science Research, v.3, n.3, p.167170, 1993.

BORGES, E.E.L.; RENA, A.B. Germinação de sementes. In: AGUIAR, I.B.; PIÑARODRIGUES, F.C.M.; FIGLIOLIA, M.B. (Coord.) Sementes florestais tropicais. Brasília: ABRATES, 1993. p.83-136.

BOUVIER, L.; CHAVAGNAT, A.; ZHANG, Y.X.; LESPINASSE, Y. Using radiography to attempt to screen for haploid embryos in apple seeds. Scientia Horticulturae, v.52, n.3, p.215-221, 1992.

BRASIL. Ministério da Agricultura e Reforma Agrária. Regras para análise de sementes. Brasília: CLAV; DNDV; SNAD; MA, 1992. 365p. 
CARMELLO-GUERREIRO, S.M. Morfologia, anatomia e desenvolvimento dos frutos, sementes e plântulas de Schinus terebinthifolius Raddi, Lithraea molleoides (Vell.) Engl., Myracrodruon urundeuva Fr. Allem. e Astronium graveolens Jacq. (Anacardiaceae). Rio Claro, 1996. 90p. Tese (Doutorado) Instituto de Biociências, Universidade Estadual Paulista "Júlio de Mesquita Filho".

CARVALHO, L.R. de. Classificação fisiológica de sementes de espécies florestais quanto à capacidade de armazenamento. Lavras, 2000. 97p. Dissertação (M.S.) - Universidade Federal de Lavras.

CARVALHO, M.L.M. de; VAN AELST, A.C.; VAN ECK, J.W.; HOEKSTRA, F.A. Pre-harvest stress cracks in maize (Zea mays L.) kernels as characterized by visual, X-ray and low temperature scanning electron microscopical analysis: effect on kernel quality. Seed Science Research, v.9, n.3, p.227-236, 1999.

CARVALHO, N.M. de; NAKAGAWA, J. Sementes: ciência, tecnologia e produção. 4.ed. Jaboticabal: Funep, 2000. 588p.

CHAVAGNAT, A. Use of soft X-ray radiography for studying seed quality in horticulture. Acta Horticulturae, n.215, p.153-158, 1987.

CHAVAGNAT, A.; LE LEZEC, M. Détermination de la valeur culturale des semences par la radiographie industrielle aux rayons X. Application aux pépins de pommier (Malus pumila Mill.). Agronomie, v.5, n.2, p.187-192, 1985.

CICERO, S.M.; VAN DER HEIJDEN, G.W.A.M; VAN DER BURG, W.J.; BINO, R.J. Evaluation of mechanical damage in seeds of maize (Zea mays L.) by X-ray and digital imaging. Seed Science and Technology, v.26, n.3, p.603-612, 1998. 
COIMBRA, R. Notas de fitoterapia. Rio de Janeiro: Laboratório Clínico Silva Araújo, 1958. p.56-59.

CÔME, D.; TISSAOUI, T. Interrelated effects of imbibition, temperature and oxygen on seed germination. In: HEYDECKER, W. (Ed.) Seed ecology. London: Butterworth, 1973. cap.9, p.157-168.

COPELAND, L.O.; McDONALD, M.B. Principles of seed science and technology. 2.ed. New York: Macmillan, 1985. 321p.

CORREAA, M.P. Dicionário das plantas úteis do Brasil e das exóticas cultivadas. Rio de Janeiro: Ministério da Agricultura e Comércio, 1926. p.170.

DAVIDE, A.C.; FARIA, J.M.R; BOTELHO, S.A. Propagação de espécies florestais. Belo Horizonte: CEMIG; Lavras: UFLA, 1995. 41p.

EGLEY, G.H. Reflections on my career in weed seed germination research. Seed Science Research, v.9, n.1, p.3-12, 1999.

FIGLIOLIA, M.B.; OLIVEIRA, E.C.; PIÑA-RODRIGUES, F.C.M. Análise de sementes. In: AGUIAR, I.B.; PIÑA-RODRIGUES, F.C.M.; FIGLIOLIA, M.B. (Coord.) Sementes florestais tropicais. Brasilia: ABRATES, 1993. p.137174.

FIGLIOLIA, M.B.; PIÑA-RODRIGUES, F.C.M. Considerações práticas sobre o teste de germinação. IF Série Registros, v.14, p.45-60, 1995.

INTERNATIONAL SEED TESTING ASSOCIATION (ISTA). International rules for seed testing. Seed Science and Technology, v.21, 363p., 1993. Supplement. 
KAMRA, S.K. Determination of germinability of cucumber seed with X-ray contrast method. Proceedings of the International Seed Testing Association, v.29, n.3, p.519-534, 1964.

KAMRA, S.K. Determination of germinability of melon seed with X-ray contrast method. Proceedings of the International Seed Testing Association, v.31, n.5, p.719-729, 1966.

LORENZI, H. Árvores brasileiras: manual de identificação e cultivo de plantas arbóreas nativas do Brasil. Nova Odessa: Plantarum, 1992. 385p.

MACKAY, D.B. The measurement of viability. In: ROBERTS, E.H. (Ed.) Viability of seeds. London: Chapman and Hall, 1974. cap.7, p.172-208.

MAGUIRE, J.D. Speed of germination: aid in selection and evaluation for seedling emergence and vigour. Crop Science, v.2, n.2, p.176-177, 1957.

MARCOS FILHO, J. Germinação de sementes. In: CICERO, S.M.; MARCOS FILHO, J.; SILVA, W.R. da. Atualização em produção de sementes. Campinas: Fundação Cargill, 1986. p.11-39.

MARCOS FILHO, J.; CICERO, S.M.; SILVA, W.R. da. Avaliação da qualidade das sementes. Piracicaba: FEALQ, 1987. 230p.

MAYER, A.M. How do seeds sense their environment? Some biochemical aspects of the sensing of water potential, light and temperature. Israel Journal of Botany, v.35, n.1, p.3-16, 1986.

MAYER, A.M.; POLJAKOFF-MAYBER, A. The germination of seeds. 2.ed. Oxford: Pergamon Press, 1975. 192p. 
MEDEIROS, A.C.S.; ZANON, A. Germinação de sementes de sapuva (Machaerium stiptatum (DC.) Vog.) e de acácia marítima (Acacia longifolia (Andr.) Wildenow). Boletim de Pesquisa Florestal, n.38, p.31-38, 1999.

NASSIF, S.M.L.; PEREZ, S.C.J.G.A. Efeitos da temperatura na germinação de sementes de amendoim-do-campo (Pterogyne nitens Tul.). Revista Brasileira de Sementes, v.22, n.1, p.1-6, 2000.

NASSIF, S.M.L; PEREZ, S.C.J.G.A. Efeitos da temperatura na germinação de sementes de amendoim-do-campo (Pterogyne nitens Tul.). Revista Brasileira de Sementes, v.22, n.1, p.1-6, 2000.

OBANDO FLOR, E.P. Danos internos de secagem avaliados pelo teste de raios-X e seus efeitos na qualidade de sementes de milho (Zea mays L.) armazenadas. Lavras, 2000. 62p. Dissertação (M.S.) - Universidade Federal de Lavras.

OLIVEIRA, E.C.; PIÑA-RODRIGUES, F.C.M.; FIGLIOLIA, M.B. Propostas para a padronização de metodologias em análise de sementes florestais. Revista Brasileira de Sementes, v.11, n.1/3, p.1-42.

OLIVEIRA, L.M. de. Avaliação da qualidade de sementes de canafístula (Peltophorum dubium (Sprengel) Taubert) pelos testes de germinação, tetrazólio e raios-X. Lavras, 2000. 111p. Dissertação (M.S.) - Universidade Federal de Lavras.

PEREZ, S.C.J.G.A.; MORAES, J.A.P.V. de. Influências da temperatura, da interação temperatura-giberelina $e$ do estresse térmico na germinação de Prosopis juliflora (Sw.) DC. Revista Brasileira de Fisiologia Vegetal, v.2, n.1, p.41-53, 1990. 
PIÑA-RODRIGUES, F.C.M.; VIEIRA, J.D. Teste de germinação. In: PIÑARODRIGUES, F.C.M. (Ed.) Manual de análise de sementes florestais. Campinas: Fundação Cargill, 1988. p.70-90.

POLLOCK, B.M. Effects of environment after sowing on viability. In: ROBERTS, E.H. (Ed.) Viability of seeds. London: Chapman and Hall, 1974. cap.6, p.150-171.

POPINIGIS, F. Fisiologia da semente. Brasília: AGIPLAN, 1977. 289p.

POULSEN, K.M.; PARRATT, M.J.; GOSLING, P.G. (Ed.) Tropical and subtropical tree and shrub seed handbook. Zürich: International Seed Testing Association, 1998. 204p.

PUKITTAYACAMEE, P.; HELLUM, A.K. Seed germination in Acacia auriculiformis: developmental aspects. Canadian Journal of Botany, v.66, n.2, p.388-393, 1988.

SAHLÉN, K.; BERGSTEN, U.; WIKLUND, K. Determination of viable and dead scots pine seeds of different anatomical maturity after freezing using the IDX method. Seed Science and Technology, v.23, n.2, p.405-414, 1995.

SANTOS, S.R.G.; AGUIAR, I.B. Germinação de sementes de branquilho (Sebastiania commersoniana (Baill.) Smith \& Downs) em função do substrato e do regime de temperatura. Revista Brasileira de Sementes, v.22, n.1, p.120-126, 2000.

SAUTON, A.; OLIVIER, C.; CHAVAGNAT, A. Use of soft X-ray technique to detect haploid embryos in immature seeds of melon. Acta Horticulturae, n.253, p.131-135, 1989. 
SIMAK, M. Testing of forest tree and shrub seeds by X-radiography. In: GORDON, A.G.; GOSLING, P.G.; WANG, B.S.P. (Ed.) Tree and shrub seed handbook. Zürich: International Seed Testing Association, 1991. p.14-1-1428.

SIMAK, M. New uses of X-ray method for the analysis of forest seed. Research Notes Royal College Reforestation, n.23, p.1-11, 1970.

SIMAK, M. X-Radiography in research and testing of forest tree seeds. Report SUAS Department of Silviculture, n.3, p.1-34, 1980.

SIMAK, M. A method for removal of filled-dead seeds from a sample of Pinus contorta. Seed Science and Technology, v.12, n.3, p.767-775, 1984.

SIMAK, M.; GUSTAFSSON, A. X-Ray photography and sensitivity in forest tree species. Hereditas, v.39, p.458-468, 1953.

SIMAK, M.; KAMRA, S.K. Comparative studies on scots pine seed germinability with tetrazolium and X-ray contrast methods. Proceedings of the International Seed Testing Association, v.28, n.1, p.3-18, 1963.

SIMAK, M.; SAHLÉN, K. Comparison between the X-radiography and cutting tests used in seed quality analysis. Seed Science and Technology, v.9, n.1, p.205-227, 1981.

SIMAK, M.; BERGSTEN, U.; HENRIKSSON, G. Evaluation of ungerminated seeds at the end of germination test by radiography. Seed Science and Technology, v.17, n.2, p.361-369, 1989.

SMITH, A.J.; GRABE, D.F. Radiographic density measurements for determination of viability and vigour in corn (Zea mays) seeds. Seed Science and Technology, v.13, n.3, p.759-768, 1985. 
SWAMINATHAN, M.S.; KAMRA, S.K. X-Ray analysis of the anatomy and viability of seeds of some economic plants. Indian Journal of Genetics \& Plant Breeding, v.21, n.2, p.129-135, 1961.

TAMBELINI, M.; PEREZ, S.C.J.G.A. Temperature limits on germination of Stryphnodendron polyphyllum Mart. Journal of Tropical Forestry Science, v.11, n.4, p.630-636, 1999.

THOMSON, J.R. An introduction to seed technology. London: Leonard Hill, 1979. 252p.

VAN DER BURG, W.J.; AARTSE, J.W.; VAN ZWOL, R.A.; BINO, R.J. Predicting tomato seedling morphology by X-ray analysis of seeds. Journal of the American Society for Horticultural Science, v.119, n.2, p.258-263, 1994.

VERTUCCI, C.W. The kinetics of seed imbibition: controlling factors and relevance to seedling vigor. In: STANWOOD, P.C.; McDONALD, M.B. (Ed.) Seed moisture. Madison: Crop Science Society of America, 1989. p.93-115. 